\title{
Terrenos tectonoestratigráficos dispersos do embasamento pré-Brasiliano (São José do Caiana, Açude Coremas e Icaiçara) na porção centro-oeste da Zona Transversal (Paraíba, Ceará e Pernambuco) Dispersed tectonostratigraphic terranes of the pre-brasiliano basement (São José do Caiana, Açude Coremas and Icaiçara) at the Central Western part of the Transversal Zone (Paraiba, Ceará and Pernambuco), Brazil
}

\author{
Benjamim Bley de Brito Neves ${ }^{1}$ (D), Cláudia Regina Passarelli' 10 \\ 1 Universidade de São Paulo, Instituto de Geociências, Rua do Lago, 562, Cidade Universitária, \\ CEP 05508-080, São Paulo, SP, BR (bbleybn@usp.br; cr.passarelli@usp.br)
}

Recebido em 27 de junho de 2019; aceito em 26 de agosto de 2020

\begin{abstract}
Resumo

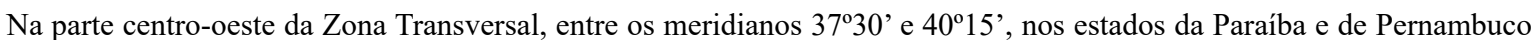
(pequena parte no Ceará), ocorrem três exposições importantes de terrenos tectonoestratigráficos (inliers) do embasamento pré-Brasiliano, ramificando faixas de dobramentos desse ciclo, delimitados por zonas de cisalhamento. Os terrenos Açude Coremas e São José do Caiana são truncados a norte pelo Lineamento Patos (E-W strike) e são separados pela zona de cisalhamento sinistral de Boqueirão dos Coxos (NE-SW strike). Para oeste (interior do Ceará), essas exposições estão bastante reduzidas em razão dos depósitos fanerozoicos da Bacia do Araripe, ficando difícil marcar o limite ocidental e as dimensões exatas do São José do Caiana. O Terreno Icaiçara, situado mais a oeste-sudoeste, é delimitado a sul pelo traço do Lineamento Pernambuco, e situa-se inteiramente no estado de Pernambuco. Esses "altos" do embasamento aparecem ramificando as exposições do Sistema de Dobramentos Piancó-Alto Brígida, e são constituídos de complexa gama de gnaisses graníticos e paragnaisses micáceos, localmente migmatizados, e com algumas poucas intercalações de supracrustais aluminosas, calciossilicáticas e anfibolíticas. Esses inliers são de idade predominantemente paleoproterozoica (Riaciana). A trama estrutural é bastante complexa, pois além de duas fases, pelo menos de dobramentos (pré-Brasilianos), há imposição dos movimentos de cisalhamento laterais, com componentes transpressionais marcantes (pelo ciclo Brasiliano). Há frações dessas rochas de embasamento acavalando as supracrustais brasilianas, como a sul do Terreno Açude Coremas, como já mencionado. Os dados geocronológicos obtidos, por diferentes métodos, indicam claramente uma idade paleoproterozoica para esses domínios de exposição de embasamento, com rara e especial ocorrência de protólito arqueano. As semelhanças nas características litoestruturais desses terrenos e sua distribuição na trama marcante de zonas de cisalhamento - demarcando-os e os separando - levam-nos a reconhecer, propor e atribuir caso típico de "dispersed ou disrupted terranes".
\end{abstract}

Palavras-chave: Zona transversal; Província Borborema; Terrenos tectonoestratigráficos; Ciclo brasiliano.

\begin{abstract}
At the central-western part of the Transversal Zone, between the $37^{\circ} 30^{\prime}$ and $40^{\circ} 15^{\prime}$ meridians, along the states of Paraíba and Pernambuco (small part in Ceará), there are three important occurrences of tectonostratigraphic terranes (inliers) of the pre-Brasiliano basement, branching out Ediacaran supracrustal belts, delimited by shear zones. The Açude Coremas and São José do Caiana terranes are truncated to the north by the Patos Lineament (E-W strike), and are separated from each other by the sinistral Boqueirão dos Coxos shear zone (NE-SW strike). Westward (to the interior of Ceará State), these exposures are quite reduced due to the fanerozoic deposits of the Araripe Basin, making it difficult to stress the western limit and exact dimensions of São José do Caiana. The Icaiçara Terrane, located more west-southwest, is bounded to the south by the Pernambuco lineament, and is located entirely in the state of Pernambuco. These tectonostratigraphic terranes are responsible for the branching out of the Piancó-Alto Brígida system into different belts and are constituted of a complex set of granitic gneisses, micaceous gneisses (paragnaisses), with local events of migmatization, associated to
\end{abstract}


some small occurrences of aluminous calc-silicatic and minor amphibolitic supracrustals rocks, Paleoproterozoic in ages. These inliers are predominantly Paleoproterozoic in age (Riaciana). The structural frame is rather complex, because besides two structural phases (at least) of folding in pre-Brasiliano times, there is the imposition of lateral shear movements, with striking transpression components (through the Brasiliano cycle). There are fractions of these basement rocks encasing the Brasiliano supracrustals, as in the south of the Açude Coremas terrane, as already mentioned. The geochronological data obtained, run by different methods, clearly indicate a Paleoproterozoic age for these domains of basement terranes, with a rare and special occurrence of Archean protolite. The similarities in the lithostructural characteristics of these lands and their distribution in the striking plot of shear zones - demarcating and separating them - lead us to recognize, propose, and assign a typical case of "dispersed or disrupted terranes".

Keywords: Transversal zone; Borborema Province; Tectonostratigraphic terranes; Brasiliano cycle.

\section{INTRODUÇÃO}

Os terrenos Açude Coremas (TAç), São José do Caiana (TSJC) e Icaiçara (TIc) ocorrem na porção centro-oeste da Zona Transversal, entre os meridianos $37^{\circ} 30^{\prime}$ e $40^{\circ} 15^{\prime}$ (Figura 1), estando bruscamente limitados a norte pelo tectonitos do Lineamento Patos, dentro do domínio do keirógeno consignado por esse lineamento transcontinental (Mataraca-Fronteiras). A zona de cisalhamento (ZC) sinistral de Boqueirão dos Coxos, de orientação NE-SW, é o limite brusco entre TSJC e TAç (Archanjo et al., 1999). O TIc (Santos, 1996) ocorre na porção mais ocidental de Pernambuco, ainda no interior da Zona Transversal, sendo truncado a sul pelos tectonitos do Lineamento Pernambuco.

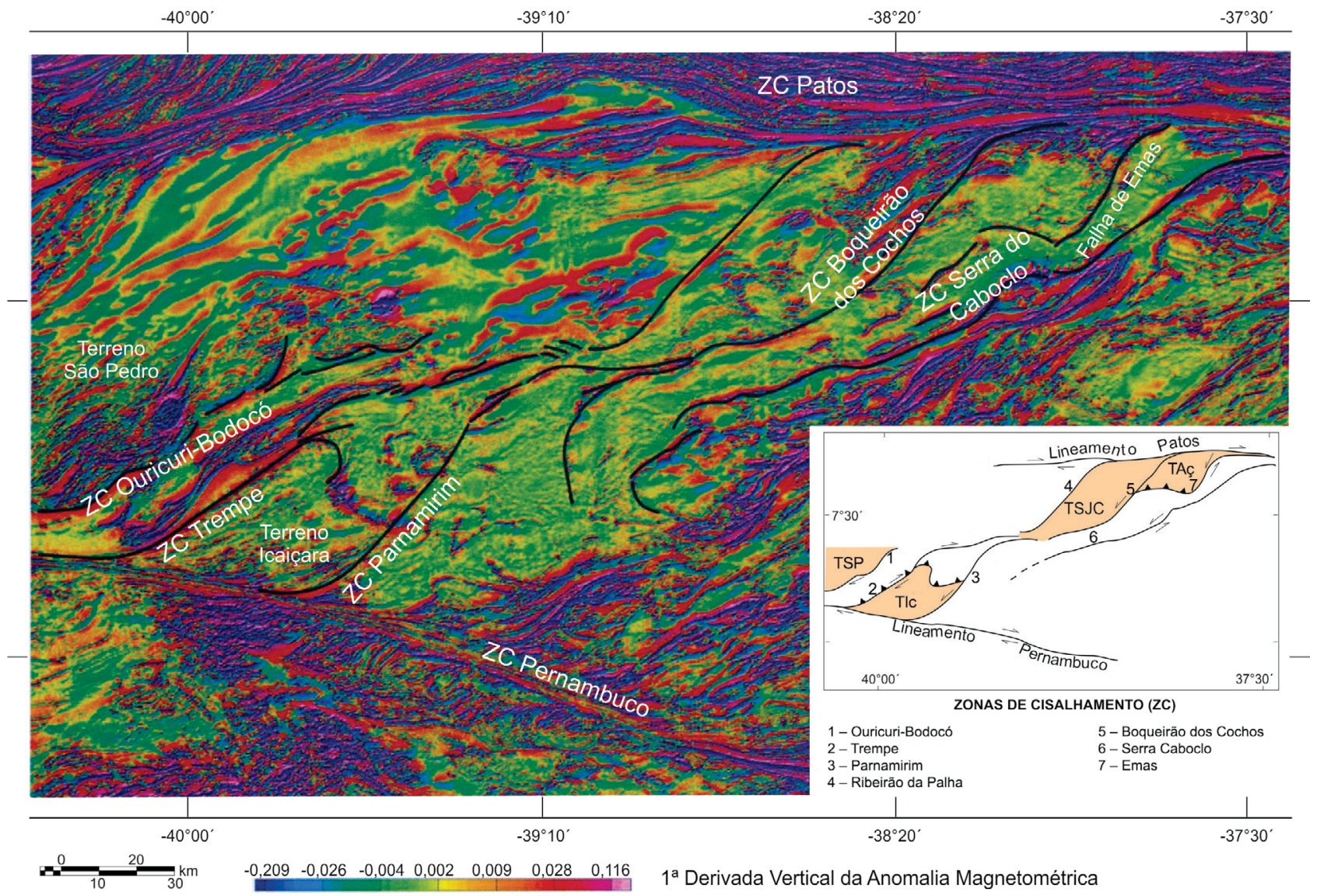

TSP: Terreno São Pedro; TIc: Terreno Icaiçara; TSJC: Terreno São José do Caiana; TAç: Terreno Açude Coremas.

Figura 1. Esquema geológico-geofísico da porção centro-ocidental da Zona Transversal (entre os lineamentos de Patos e Pernambuco), mostrando a distribuição das zonas de cisalhamentos principais e os terrenos dispersos entre elas, então posicionados. Imagem aeromagnetométrica cedida pelo Serviço Geológico do Brasil (CPRM), na pessoa do geólogo Roberto Gusmão de Oliveira. 
As ZCs/falhas que o delimitam a oeste (ZC Trempe) e leste (ZC Parnamirim) mostram continuidade para o norte apresentando junção com aquelas que delimitam os terrenos situados mais a norte, anteriormente mencionados (TAç $\mathrm{e}$ TSJC) (Figura 1).

Pela natureza das litologias pré-brasilianas expostas e seus respectivos dados geocronológicos, a serem aqui discutidos, e ainda pela presença da ZC comum os delimitando, é bem possível que, na realidade, tenhamos tido no passado geológico um terreno composto ou superterreno prévio, que veio a ser dispersado no final do Neoproterozoico, formando os terrenos anteriormente mencionados, tipificando assim um caso dispersed terranes, conforme a bibliografia mais moderna (Gibbons, 1994). De fato, são exposições francas atuais do embasamento, em três áreas de afloramentos distintas (delimitadas por falhamentos importantes), sendo essas exposições que apresentam litotipos praticamente de mesma natureza (algumas diferenças pequenas), estrutura e idade. Considerando a observação de que essas áreas distintas de exposição do embasamento foram condicionadas francamente por deslocamentos tardios de ZCs, chegam-se a reunir, assim, as características de "terrenos dispersos" (ou disrupted terranes), consoante descritos e propostos por Gibbons (1994) e Howell (1995), entre outros autores.

Para oeste e sudoeste no sentido do Ceará, o TSJC é recoberto quase inteiramente por sedimentos fanerozoicos da Bacia do Araripe, sob a qual deve estar também encoberto seu limite mais ocidental, que não conseguimos determinar com a precisão desejada. Isso é dito porque, conforme verificamos in loco, quando aparecem as primeiras exposições de litologias de embasamento da bacia sedimentar, mais para oeste e sudoeste, essas são de contextos litológicos já de supracrustais neoproterozoicas, de ramos do Sistema de Dobramentos Piancó-Alto Brígida (SPAB). Uma conexão prévia entre esses "altos do embasamento" da Paraíba e do Ceará - TSJC e TAç, com aquele do oeste de Pernambuco (TIc), aqui discutidos - pode ser preconizada, sem muitos problemas, conforme esquematizado na Figura 1, e consoante àqueles contextos litoestruturais neles registrados. Os levantamentos geofísicos atualmente disponíveis (gravimétricos, aeromagnéticos) e os levantamentos de campo parecem comprovar a existência prévia dessa conexão. Porém, como dito, toda porção ocidental do TSJC é recoberta por sedimentos fanerozoicos, e do outro lado das ocorrências dos sedimentos fanerozoicos (já no estado do Ceará), já não mais aparecem rochas do embasamento mais antigo, e sim algumas exposições de metassedimentos de baixo grau do Supergrupo Santana dos Garrotes (do SPAB).

As constituições litoestruturais dos três terrenos mostram algumas afinidades interessantes (gnaisses graníticos + migmatitos + supracrustais paleoproterozoicas, cortados por inúmeros granitoides brasilianos), que foram nomeadas informalmente em comum (integração 1/250.000 de Gomes, 2000, 2001).

Entretanto, há ainda uma série de pequenas dúvidas e esparsas diferenças a serem equacionadas, o que não foi possível ainda na escala atual de semidetalhe (sob a qual trabalhamos). Logo, o tratamento e a discussão em separado desses terrenos (por enquanto) são o caminho mais indicado. Mormente, no caso do TIc, onde há indicações geológicas (parte já discriminada, com ajuda do levantamento geocronológico) de ocorrência peculiar de supracrustais neoproterozoicas (nappismo?) sobrepostas localmente aos litotipos de embasamento paleoproterozoico, como será destacado a posteriori.

Uma característica comum a ser destacada é a presença de stocks e batólitos graníticos do arco magmático ediacarano (Brito Neves et al., 2016), que baliza subparalelamente, a sul do Lineamento Patos, com muitas ocorrências dos tipos clássicos (da Zona Transversal, parte norte) de granitos desse arco ("Conceição", "Itaporanga"), que pelas suas dimensões e características gerais, impuseram notório componente tectonotermal em todos os terrenos.

A concepção de terrenos tectonoestratigráficos do embasamento para esses altos (maciços) inliers é relativamente recente. A identificação das características de um terreno tectonoestratigráfico para o TIc já fora proposta por Santos et al. (1997). Para o caso do TSJC, isso começou a ser considerado apenas após 2003 (depois da tese de Kozuch, 2003) e na síntese de Brito Neves et al. (2018).

Para o TAç, essa concepção de terreno tectonoestratigráfico paleoproterozoico está sendo agora introduzida, após reflexão sobre a natureza do embasamento, sua posição no contexto tectônico regional e pelas primeiras determinações de idade U-Pb dele (e seu contato cavalgante sobre as supracrustais brasilianas). Até recentemente, pensava-se que todo o domo estrutural (onde se situa o TAç, em sua maior parte) pertencia ao contexto litoestrutural das supracrustais do SPAB. Os trabalhos de Bittar (1998), Gomes (2000) e Medeiros (2004) foram muito importantes para lastrear a verificação de presença de rochas pré-brasilianas, paleoproterozoicas (só agora confirmada pela geocronologia). Assim sendo, a incorporação do TAç como alto do embasamento paleoproterozoico está sendo formalizada nessa oportunidade - embora previamente tenha havido algumas sugestões inéditas nesse sentido.

Além das semelhanças gerais já apontadas (em constituição litoestrutural e dados geocronológicos), na observação/reconstituição zenital desses terrenos em cartas aerofotogeológicas, de modelo digital de terreno e geofísicos (ternário, aeromagnetométrico e gravimétrico), fica muito interessante o arranjo deles entre falhas de rejeito direcional (direção NE-SW predominante), balizadas pelos grandes lineamentos regionais, subsidiários das ZCs de Patos (a norte) e Pernambuco (a sul), estas de direções gerais 
E-W e caráter destral conspícuo (os quais delimitam a Zona Transversal, Figura 1).

\section{TERRENO AÇUDE COREMAS}

O terreno em epígrafe (Figura 2) foi escolhido para designar uma área poligonal irregular, dômica (polígono com eixo maior $\mathrm{NW}-\mathrm{SE} \cong 31 \mathrm{~km}$ ), expondo o embasamento das supracrustais brasilianas (do SPAB) que circunscrevem - a sul e a leste - a referida área dômica, e que soma uma extensão geral próxima a $1.000 \mathrm{~km}^{2}$, e está situada na porção centro-norte do estado da Paraíba (o que equivale à posição centro-noroeste da Zona Transversal).
Essa forma poligonal atual (e as deformações a ela impostas) foi consignada pelas ações das ZC neoproterozoicas de Patos - limite norte, direção E-W, de caráter destral — e de Boqueirão dos Coxos - limite ocidental, direção NE-SW, de caráter sinistral - e em parte da ZC de Emas - limite oriental, direção NE-SW, também de caráter sinistral. De forma que a porção sul desse polígono irregular é marcada por uma resultante zona de empurrão, que desloca parcialmente essas unidades/rochas pré-neoproterozoicas (do terreno) por sobre as supracrustais de mais baixo grau do Ciclo Brasiliano (do contexto do SPAB). Embora seja uma entidade geotectônica de substrato paleoproterozoico (como pretendemos demonstrar), é necessário alertar desde já que toda a forma, a posição e a ordenação estrutural desse

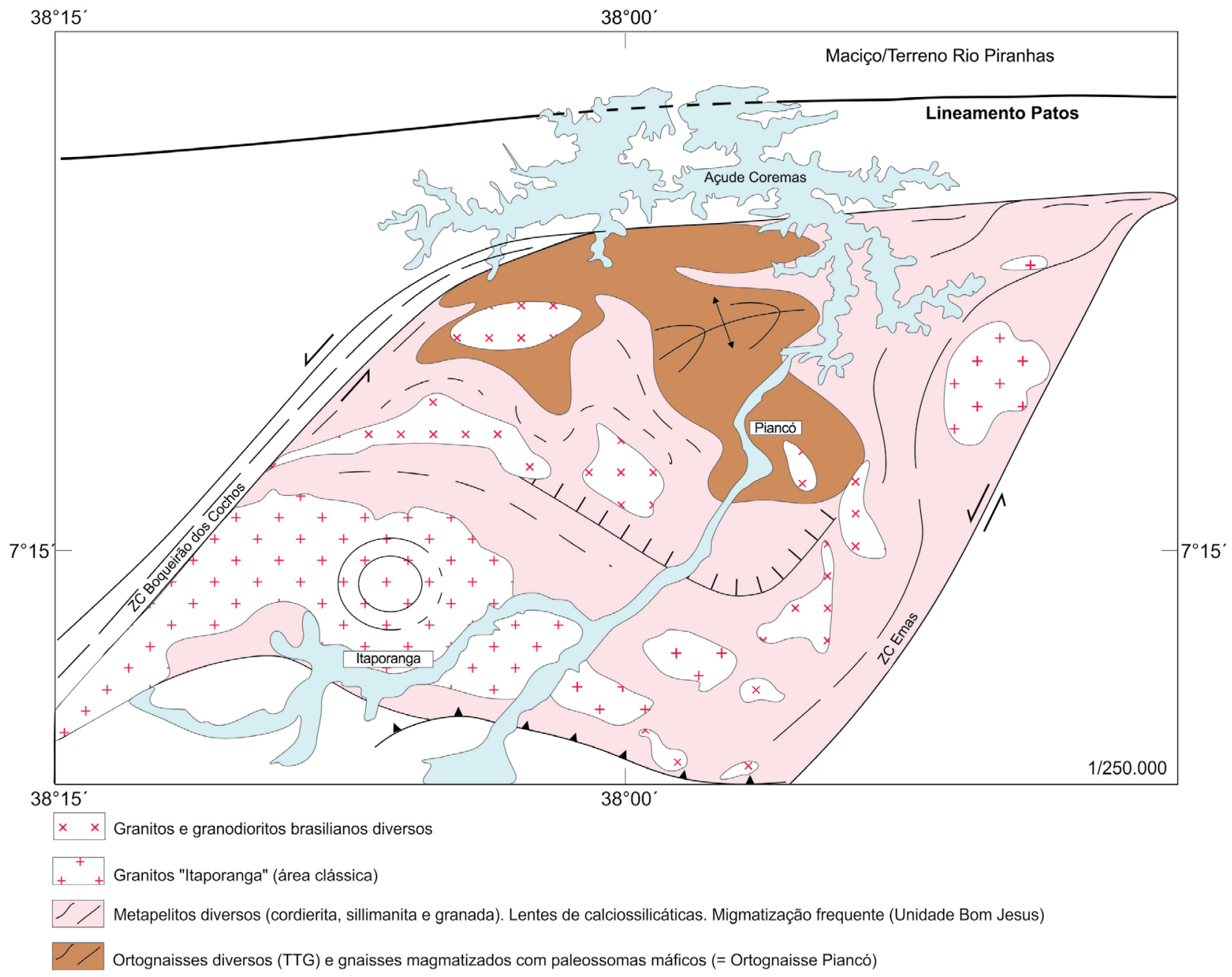

ZC: Zona de Cisalhamento; TTG: tonalito-trondhjemito-granodiorito.

Fonte: Gomes (2000) e Medeiros (2004).

Figura 2. Esquema geológico do Terreno Açude Coremas. Terreno situado na porção centro-noroeste da Zona Transversal, entre as zonas de cisalhamento de Boqueirão dos Cochos (a oeste) e Emas (a leste), imediatamente a sul do Lineamento de Patos, inteiramente no estado da Paraíba (a sudoeste). 
terreno foram impostas pela trama de cisalhamentos associada ao Lineamento Patos, no final do Neoproterozoico. A disposição entre ZCs e a possibilidade vislumbrada de uma antiga conexão desse terreno (junto ao TSJC) com o TIc (centro-oeste de Pernambuco, dentro da Zona Transversal), leva-nos a utilizar a conotação "terrenos dispersos" para eles. Feições gerais (litológicas e estruturais) semelhantes são apontadas em vários sistemas orogênicos do mundo.

Dois contextos litoestruturais principais se acham expostos nessa área dômica. Na parte mais central (incluindo a cidade de Piancó e a porção mais a sul-sudeste da Barragem de Coremas), afloram ortognaisses do tipo tonalito-trondhjemito-granodiorito (TTG) (Medeiros, 2004) com algumas porções migmatizadas e expondo algumas intercalações de rochas anfibolíticas e calciossilicáticas (contexto que foi, então, epigrafado de "Ortognaisses de Piancó" - PPp). $\mathrm{Na}$ parte mais externa, contornando o polígono, afloram rochas metassedimentares diversas (paragnaisses s.l.), com predomínio de metapelíticas, com cordierita, granada e até sillimanita, com várias porções fracamente migmatizadas. A presença de estruturas migmatíticas estromatíticas é frequente, e isso permite diferenciar essas rochas de embasamento das supracrustais brasilianas do contorno do domo (sempre em baixo grau). Essa diferença no grau de metamorfismo em contextos de idades distintas nem sempre foi considerada objetivamente. Algumas intercalações calciossilicáticas (mármores, inclusive) e anfibolíticas costumam também ocorrer nessa unidade (que foi informalmente designada de "Paragnaisses de Bom Jesus" (PPbj) por Medeiros, 2004).

Essas duas unidades, PPp e PPbj, foram atribuídas no passado (então sem dados geocronológicos concretos ainda) ao Mesoproterozoico (Gomes, 2001) e, depois, ao Paleoproterozoico - por Medeiros (2004), que as nomeou, como mencionado anteriormente -, o que veio a ser confirmado agora, neste trabalho.

Bittar (1998) não discriminou unidades e chamou todas em conjunto de "Sequência Piancó". Gomes (2000) havia considerado essas unidades como do Mesoproterozoico (respectivamente discriminadas em mapa 1/250.000 como "Mpl" e "Mp2"), sem nenhum dado geocronológico para se balizar. Já no mapa geológico da Paraíba (Santos et al., 2002), está registrado com ênfase na presença das rochas mais antigas desse terreno na área (então designado "Complexo Piancó"). Essas ocorrências foram atribuídas ao PaleoproterozoicoMesoproterozoico, o que não veio a se confirmar, como pretendemos demonstrar no presente trabalho.

É justo acrescentar que as primeiras publicações citando o predomínio de litologias paleoproterozoicas para todos os três terrenos aqui discutidos foram os trabalhos de Van Schmus et al. (2011) e Santos et al. (2014), baseados em informações geocronológicas preexistentes, algumas delas então inéditas (ou de divulgação restrita).
Essas unidades litoestratigráficas do TAç estão recortadas por vários stocks graníticos de diversas naturezas: alguns deles são granitos, granodioritos e quartzo monzonitos ("tipo Itaporanga"). No corner sudoeste do terreno, encontra-se o clássico batólito de Itaporanga (granito, granodiorito, quartzo monzonito), caracterizado por seus fenocristais de feldspato potássico de até decímetros - trata-se de uma unidade clássica da literatura geológica nordestina, tratada por muitos autores, em diferentes oportunidades. Mariano (1989), em sua tese de Doutorado, demonstrou a presença de contatos complexos, interdigitados com as rochas do embasamento paleoproterozoico.

Além das semelhanças gerais já apontadas (em constituição litoestrutural e dados geocronológicos) para esse terreno e os demais assinalados, a mesma informação (sobre a presença de stocks e batólitos variados) é válida. Essas rochas intrusivas são presumidas como originadas do desenvolvimento do arco magmático ediacarano, já mencionado (Brito Neves et al., 2016), situado ao longo da parte norte da Zona Transversal.

Por essas características gerais anteriormente discutidas e por razões descritivas é que achamos bastante possível que os dois "altos"/inliers, aqui tratados em separado (TAç e TSJC), compartilharam no passado do mesmo contexto de embasamento pré-Brasiliano, tendo sido seccionados e separados de forma brusca pela ZC de Boqueirão dos Coxos. Em várias cordilheiras orogênicas do mundo, casos semelhantes têm sido mencionados, e a designação de terrenos tectonoestratigráficos dispersos tem sido a mais indicada.

\section{Unidades litoestruturais}

Medeiros (2004) destacou e discriminou cartograficamente os "Ortognaisses Piancó", com a designação PPp, ao aludir a porção mais interna do terreno - que, como um todo, fora chamado indevidamente de "Complexo Caicó" por Bittar (1998). Essa unidade ocorre principalmente das imediações sul-sudeste da cidade de Piancó, e daí até a porção a sul do Açude Coremas (Figura 2). Esse contexto é marcadamente formado por rochas gnáissicas, de natureza granítica, granodiorítica e tonalítica, geralmente de granulação média, com migmatização frequente, e que são consideradas rochas intrusivas de provável origem em um arco magmático do Riaciano. Essa é uma hipótese de trabalho que está sendo testada em todos os terrenos do interior da Zona Transversal (projeto de pesquisas em andamento), com muitos dados já levantados e outros em estudo. Nessa unidade, lateralmente há gradações para rochas migmatíticas, ora com estruturas muito complexas, ora com estruturas bandadas relativamente simples, em que se destacam bandas escuras decimétricas de anfibolito e bandas claras graníticas e granodioríticas (Figura 3). Essa unidade está muito bem descrita na tese de Medeiros (2004). 


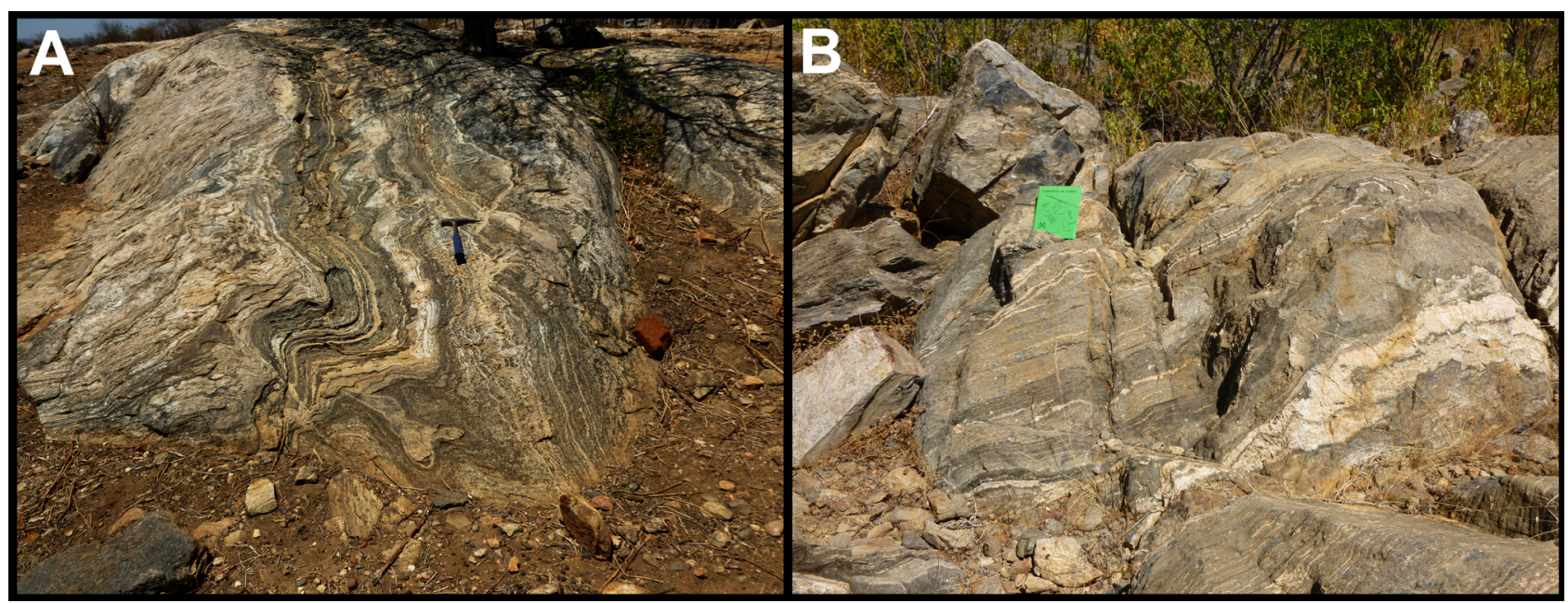

Figura 3. (A) Pedreira Carrapateiras (amostra PAPE-184) na estrada Piancó-Coremas. Complexo migmatítico intensamente dobrado, com paleossoma granodiorítico e várias gerações neossomáticas. Vide Figura $5 \mathrm{C}$ (idade U-Pb $2135 \pm 8 \mathrm{Ma}$ ); (B) migmatitos da Pedreira Pendência (amostra PAPE-182) nas imediações da Vila de Pendência (Coremas, Paraíba), na porção N-NE do Terreno Açude Coremas. É possível verificar tratos paleossomáticos granodioríticos e anfibolíticos predominantes, e uma participação secundária das porções quartzo-feldspáticos. Vide Figuras 4 e 5.

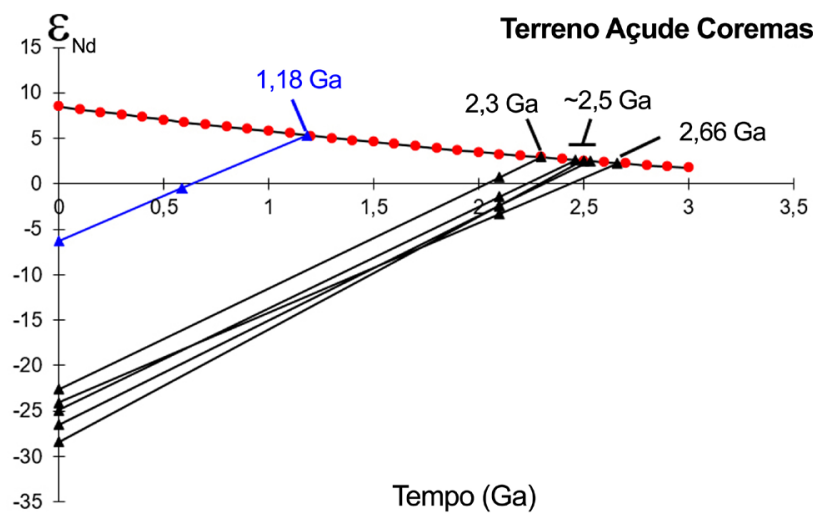

Figura 4. Diagrama de evolução $\varepsilon_{\mathrm{Nd}}$ versus tempo (Ga) do Terreno Açude Coremas. Curva do manto empobrecido (DePaolo, 1988).

A unidade posicionada nas porções mais externas do terreno (Figura 2) é constituída essencialmente de rochas para-derivadas, e que foram designadas em conjunto de "Paragnaisses de Bom Jesus" (PPbj). Essas rochas estão dispostas circunscrevendo toda a forma poligonal do terreno, e estão intrudidas na porção sudoeste pelo clássico "batólito de Itaporanga". Esse contexto é marcado pela presença de rochas metassedimentares, destacando-se, sobretudo, as metapelíticas (metamorfizadas na fácies anfibolito, com anatexia frequente), com a presença de granada, cordierita e sillimanita. Subordinadamente, há algumas ocorrências de rochas calciossilicáticas, incluindo alguns mármores e, mais restritamente, alguns anfibolitos. Em alguns locais, esses metassedimentos apresentam também feições litoestruturais migmatíticas. As porções de fácies metamórficos mais baixas foram a causa da dificuldade (ou demora) de reconhecimento e discriminação dessa unidade daquelas supracrustais neoproterozoicas do sistema de dobramentos brasiliano (SPAB), que circunscreve o terreno.

Como já mencionado, diversos stocks granitoides recortam as unidades PPp e PPbj, devendo ser destacado o alojamento intrusivo portentoso do "Granito Itaporanga" (clássico da bibliografia geológica da Província Borborema), no canto sudoeste da forma poligonal do terreno. Esse batólito, foco de vários trabalhos científicos graças às suas peculiaridades, é constituído de rochas graníticas, granodioríticas e quartzo monzoníticas, destacadamente porfiríticas. Os cristais de feldspato potássico podem localmente atingir dimensões decimétricas, com arranjos diversos, inclusive, com destacável orientação linear.

Há uma série grande de trabalhos enfocando esse granito, na sua área típica, mas também em várias outras áreas dentro e fora da Zona Transversal. Gostaríamos de destacar que observamos localmente a presença de contatos interdigitados da rocha grossa ígnea com as suas encaixantes, com vários aspectos interessantes, inclusive simulando estruturas migmatíticas (como classicamente essas eram consideradas/reportadas).

Do ponto de vista estrutural, nas unidades descritas anteriormente, pode ser verificado um sistema de dobramentos (de segunda ou terceira geração) da foliação predominante $\left(\mathrm{S}_{\mathrm{n}}\right)$, com dobras relativamente apertadas e subparalelas 


\section{Terreno Açude Coremas}
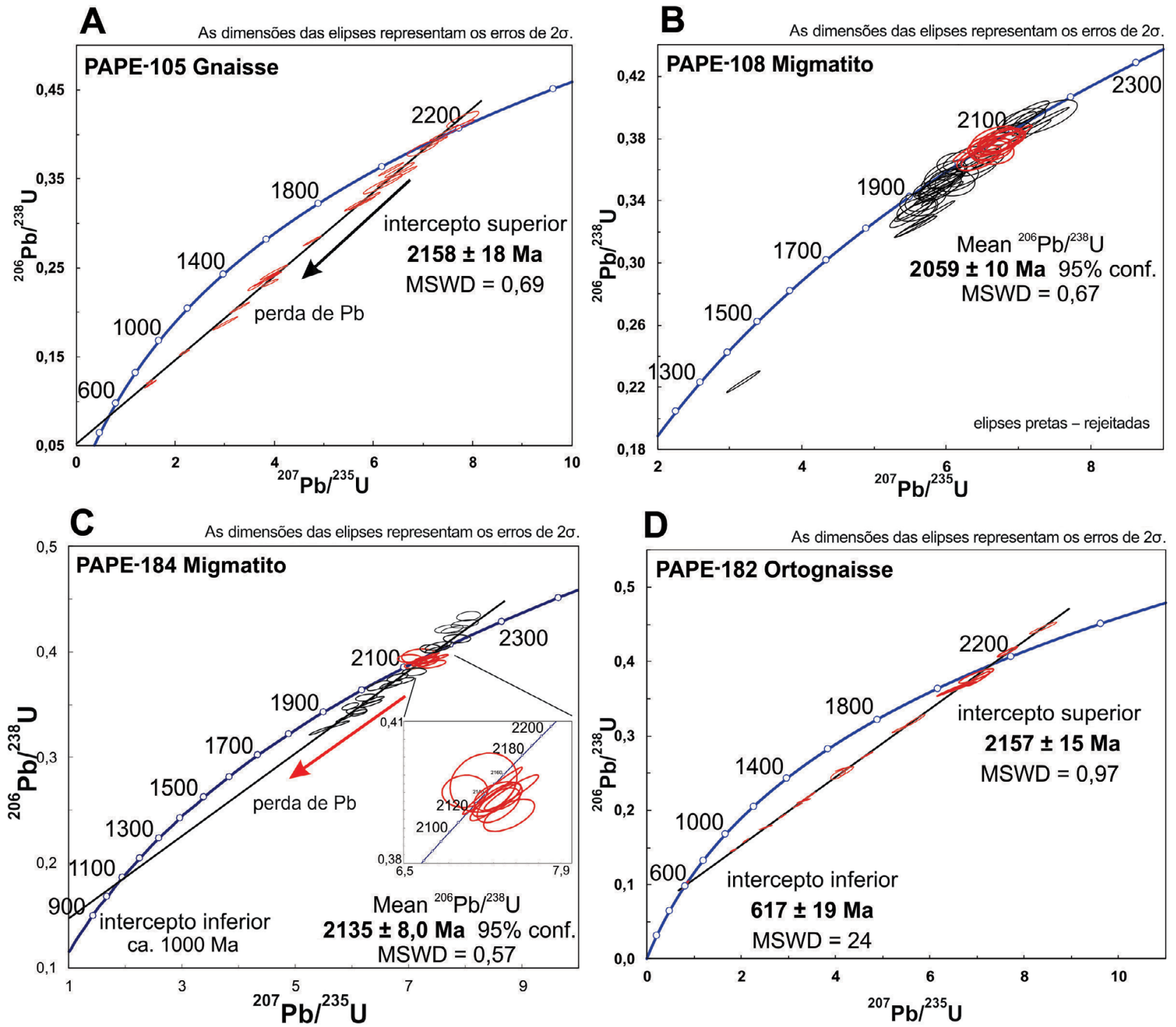

MSWD: mean square weighted deviation

Figura 5. Diagramas Concórdia (U-Pb em zircões) dos gnaisses do embasamento - Terreno Açude Coremas. (A) Amostra PAPE-105; (B) amostra PAPE-108; (C) amostra PAPE-184; (D) amostra PAPE-182.

$\left(\mathrm{D}_{\mathrm{n}+1}\right)$ que expõem estruturas antiformais e sinformais, de direção geral E-W, com variações para NW-SE. Para se falar nesse dobramento da foliação e suas direções, não se pode omitir as injunções estruturais impostas. Esse dobramento, na orientação e tipologia apresentadas, dependeu muito da última forma impingida pelos grandes lineamentos (com expressivas zonas de milonitização) que demarcam a área poligonal do terreno: a norte o Lineamento Patos (movimento destral de destaque); a sudoeste o Lineamento
Boqueirão dos Coxos (sinistral); e a este-nordeste, a ZC de Emas (também destral).

\section{Determinações Sm/Nd}

Cerca de uma dezena de amostras foi coletada das unidades litoestruturais que compõem o TAç, cujos resultados analíticos estão apresentados na Tabela 1, e com representação gráfica na Figura 4. 
Tabela 1. Dados analíticos das determinações Sm-Nd nas rochas do Terreno Açude Coremas.

\begin{tabular}{|c|c|c|c|c|c|c|c|c|c|c|c|c|c|}
\hline Amostra & Rocha & Local & $\begin{array}{l}\text { Coorde- } \\
\text { nadas }\end{array}$ & $\begin{array}{c}\text { Sm } \\
(p p m)\end{array}$ & $\begin{array}{c}\mathrm{Nd} \\
(\mathrm{ppm})\end{array}$ & ${ }^{147} \mathrm{Sm} /$ & ${ }^{143} \mathrm{Nd} /$ & $\varepsilon(0)$ & $\begin{array}{c}\mathrm{F} \\
\mathrm{Sm} / \\
\mathrm{Nd}\end{array}$ & $\begin{array}{c}\mathrm{T}_{\mathrm{DM}} \\
(\mathrm{Ma})\end{array}$ & $\begin{array}{c}\varepsilon \\
\left(T_{D M}\right)\end{array}$ & $\begin{array}{c}\mathrm{T} 1 \\
(\mathrm{Ma})\end{array}$ & $\begin{array}{c}\varepsilon \\
\text { (T1) }\end{array}$ \\
\hline $\begin{array}{l}\text { SPAB Mx } \\
\text { NPi }\end{array}$ & Biognaisse & $\begin{array}{l}\text { Norte } \\
\text { Piancó }\end{array}$ & & 43 & 37,729 & 0,1191 & 0,51 & $-24,07$ & $-0,39$ & ,3 & 2,28 & .100 & $-3,28$ \\
\hline PAPE-180 & Ortos & $\begin{array}{c}\text { Sul } \\
\text { Garimpo }\end{array}$ & & 2442 & 13,81 & 0,1069 & 0,5 & $-26,47$ & $-0,46$ & 9 & 2,50 & 00 & $-2,42$ \\
\hline PAPE-182 & Gnaisse & Pendência & $\begin{array}{l}9219420 \\
6343480\end{array}$ & 3,809 & 23,106 & 0,0997 & 0,511183 & $-28,38$ & $-0,49$ & 9,7 & 2,55 & .100 & $-2,40$ \\
\hline PAPE-183 & Ortognaisse & $\begin{array}{c}\text { NW } \\
\text { Pendência }\end{array}$ & $\begin{array}{l}9218496 \\
6323870\end{array}$ & 1,608 & 8,929 & 0,1089 & 0,511362 & $-24,89$ & $-0,45$ & 7,1 & 2,63 & 2.100 & $-1,37$ \\
\hline PAPE-260 & Biognaisse & $\begin{array}{c}1 \mathrm{~km} \mathrm{E} \\
\text { Itaporanga }\end{array}$ & $\begin{array}{l}9119965 \\
6060350\end{array}$ & 6,828 & 34,678 & 0,1191 & 0,512315 & $-6,30$ & $-0,39$ & $1.173,4$ & 5,32 & 600 & $-0,36$ \\
\hline PAPE-261 & Biognaisse & PB-342 & $\begin{array}{r}9207454 \\
6111683 \\
\end{array}$ & 2,442 & 13,446 & 0,1098 & 0,511482 & $-22,55$ & $-0,44$ & $2.298,0$ & 2,92 & 2.100 & 0,72 \\
\hline
\end{tabular}

SPAB: Sistema de Dobramentos Piancó-Alto Brígida.

Entre as seis amostras analisadas, cinco apresentam seus protólitos diferenciados do manto entre o Neoarqueano e o Paleoproterozoico (Riaciano), com valores de $\mathrm{T}_{\mathrm{DM}}$ entre 2,3 e 2,66 Ga - maior concentração em torno de $2,5 \mathrm{Ga}$ (Figura 4). O biotita-gnaisse laminado (PAPE-260) que está na zona de contato do Granito Itaporanga ( $584 \mathrm{Ma}$ - Brito Neves et al., 2003) com o embasamento do TAç apresenta $\mathrm{T}_{\mathrm{DM}}$ esteniano, diferenciando-se dos litotipos do embasamento. Os valores fracamente negativos a positivos de $\varepsilon_{\mathrm{Nd}}(\mathrm{t})$ entre $-3,2$ e 0,7 neste gnaisse indicam contribuições de propriedades juvenis com pequena contribuição crustal, em quantidades muito próximas. A influência do tempo e do histórico litoestrutural do Brasiliano está expressa nos elevados valores negativos do $\varepsilon_{\mathrm{Nd}(0)}$ nas amostras de idades 2,1 Ga (Tabela 1).

\section{Determinações U-Pb}

\section{Discussão dos dados U-Pb do Terreno Açude Coremas}

No contexto do TAç, quatro localidades foram selecionadas para determinações U-Pb (cujos resultados analíticos se encontram no Documento Suplementar - Tabela 1):

- A primeira amostra, PAPE-105, gnaisse bandado (em parte protomilonítico) a $3 \mathrm{~km}$ da cidade de Piancó (coordenadas 9205178 - 621027);

- A segunda amostra, PAPE-108, representa fácies diatexíticas de um complexo gnáissico migmatítico, no extremo noroeste da área dômica, situada pouco ao sul-sudoeste da cidade de Coremas (coordenadas 9211042 - 612283);

- A terceira amostra, PAPE-184 (Figura 3A), representa a porção diatexítica de rochas migmatíticas da Pedreira Carrapateiras, localizada um pouco mais a sul da PAPE-108, na localidade Carrapateiras (coordenadas $9211082-612272)$;

- A quarta amostra, PAPE-182, foi coletada na pedreira da Vila de Pendência (Figura 3B), na fração paleossomática-metaquartzo-diorítica de rochas migmatíticas a norte-nordeste do terreno (coordenadas 921942 -634348).

As três primeiras amostras foram coletadas dentro do contexto litoestrutural mais central do terreno, dentro da unidade que fora chamada de "PPp". Já a quarta amostra foi coletada a nordeste da área dômica (localidade de Pendência), do contexto que fora chamado de "PPbj", que ali se encontra bastante migmatizado.

Os resultados obtidos mostram notável coerência, sinalizando idade do Riaciano Superior para esses litotipos (para todas essas unidades litoestratigráficas, ainda informalmente tratadas). Como esperado e observado em todos os gráficos obtidos, a importância do retrabalhamento pelo Ciclo Brasiliano é marcante em todas as concórdias traçadas.

Os cristais de zircão analisados do gnaisse bandado (amostra PAPE-105), apesar de apresentarem perda contínua $\mathrm{de} \mathrm{Pb}$, alinham-se em corda cujo intercepto inferior aponta para evento tectonotermal Brasiliano. O intercepto superior indica idade de cristalização em $2158 \pm 18 \mathrm{Ma}$ (Figura 5A). Os cristais de zircão com discordância reversa não foram utilizados nos cálculos.

A segunda amostra (PAPE-108), parte diatexítica de um migmatito, apresentou uma série de zircões mais ou menos concordantes, com idade bem marcada de $2059 \pm 10 \mathrm{Ma}$, ou seja, no limite Riaciano-Orosiriano (Figura 5B).

A idade de cristalização da porção diatexítica de rochas migmatíticas da Pedreira Carrapateiras, amostra PAPE-184 (Figura 3A) de $2135 \pm 8 \mathrm{Ma}$, foi obtida por meio da média 
ponderada das idades ${ }^{206} \mathrm{~Pb} /{ }^{238} \mathrm{U}$ (Figura 5C). Os cristais de zircão analisados apresentam perda contínua de $\mathrm{Pb}$, e quando analisados em conjunto, alinham-se em discórdia cujo intercepto superior apresenta a mesma idade obtida pela média ponderada referida anteriormente, mas com erros maiores e intercepto inferior apontando para idade em torno de $1000 \mathrm{Ma}$, com erros elevados.

A quarta amostra, PAPE-182 (Figura 3B), representa a fração paleossomática (metaquartzo-diorítica) dos migmatitos. Os cristais de zircão analisados apresentam perda contínua de $\mathrm{Pb}$ e alinham-se em discórdia cujo intercepto superior apresenta idade de $2157 \pm 15 \mathrm{Ma}$. Para esse cálculo foram utilizadas as frações mais próximas à Concórdia (elipses cheias - Figura 5D). Quando analisadas todas as frações, a discórdia apresenta intercepto inferior em $617 \pm 19 \mathrm{Ma}$, que apesar do alto erro, aponta claramente para evento tectonotermal Brasiliano.

Os gnaisses bandados protomiloníticos da cidade de Piancó (PAPE-105), os diatexitos de Carrapateiras (PAPE-184) e a porção paleossomática dos migmatitos da pedreira da vila de Pendência (PAPE-182) apresentam idade Riacina de 2,1 Ga. As amostras PAPE-105 e PAPE-182 mostram claramente evidências de abertura do sistema isotópico $\mathrm{U}-\mathrm{Pb}$ decorrentes de superimposição de evento tectonotermal Brasiliano, em torno de $600 \mathrm{Ma}$ - diferentemente da amostra PAPE-184, que apresenta sugestão de superimposição de evento toniano. Apesar da grande incerteza desse dado, esse fato não deve ser totalmente descartado, visto que no TIc há registro Toniano em rochas gnáissicas (Complexo Barro), a serem discutidas a posteriori.

O evento Toniano está bem registrado na Zona Transversal da Província Borborema em granitoides, hoje augen-gnaisses e migmatitos, com idades entre 870 e $1000 \mathrm{Ma}$ (Guimarães et al., 2012). O evento Toniano, denominado "Evento Cariris Velhos", está representado na Subprovíncia Transversal principalmente por rochas metavulcânicas bimodais, incluindo variedades piroclásticas e plútons graníticos, hoje ortognaisses (Brito Neves et al., 2001; Kozuch, 2003; Guimarães et al., 2012).

A amostra de diatexito da área dômica (PAPE-108) se difere das demais por apresentar pouca perda de $\mathrm{Pb}$ e idade um pouco mais jovem, do limite Riaciano-Orosiriano (2059 Ma).

\section{TERRENO SÃO JOSÉ DO CAIANA}

Além de constituir um proeminente "alto estrutural", separando contextos distintos do SPAB, a presença de rochas pré-tonianas, mais especificamente paleoproterozoicas, é característica marcante desse inlier. Isso foi identificado preliminarmente por Kozuch (2003), em sua tese de Doutorado (determinação U-Pb TIMS, amostra 96-282, em gnaisses, próximo à cidade topônima).
Esse terreno se expõe em uma área aproximadamente sigmoidal de direção NE-SW com extremidades a sul do Açude Coremas (a N-NE, ca. meridiano $38^{\circ} 00^{\prime}$ ) e a norte da fronteira CE-PE (a S-SW), consignando uma área total de aproximadamente $1.300 \mathrm{~km}^{2}$, em grande parte no noroeste da Paraíba e com pequena parte no sudeste do Ceará (Figuras 1 e 6). A sua porção para oeste e sudoeste se encontra parcialmente encoberta por terrenos sedimentares jurássicos, que são parte da sequência pré-rifte das bacias mesozoicas ditas interiores (no caso, Bacia do Araripe) e costeiras da margem equatorial brasileira. Tanto a norte quanto a sul da fronteira PB-CE é que reaparecem as supracrustais brasilianas. Ou seja, cerca de $90 \%$ desse terreno tectonoestratigráfico se acha bem exposto em território paraibano (sudoeste do estado), mas em grande parte encoberto pelos depósitos fanerozoicos do Araripe (mais para o lado cearense).

Para o lado cearense, no embasamento (ocasionalmente) das ocorrências sedimentares do Araripe (de Mauriti a Iara, no Ceará), afloram amplamente os metalaminitos (predominam rochas argilosas finamente estratificadas) do "Supergrupo Santana dos Garrotes", na designação original de Bittar (1998), parte do contexto do SPAB. Ou seja, o embasamento paleoproterozoico do TSJC não chega até aquelas cidades. A extensão para sudoeste do terreno não

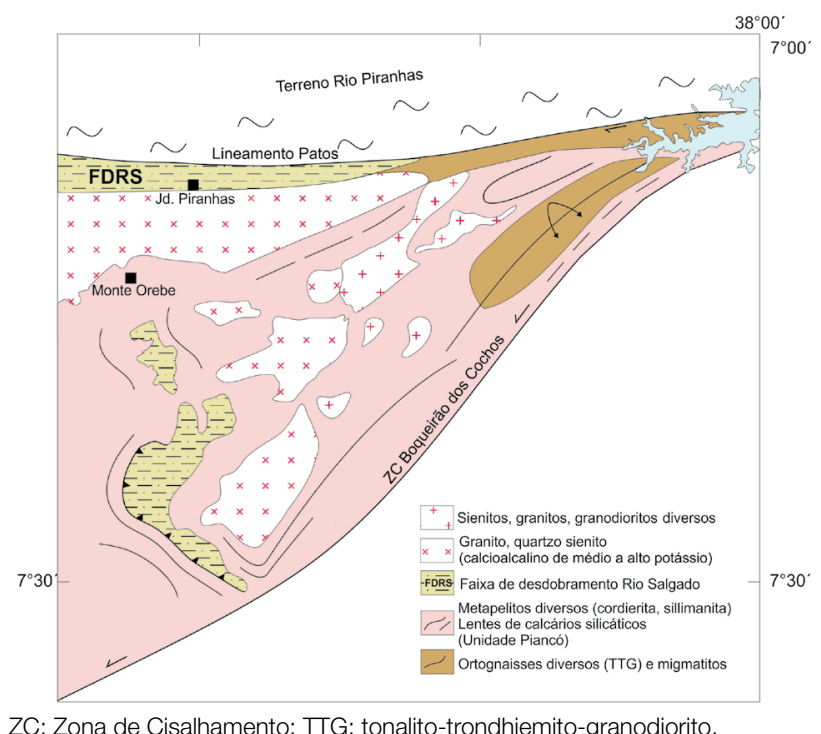

Figura 6. Esquema geológico do Terreno São José do Caiana, baseado em Gomes (2000), Medeiros (2004) e em nossas observações de campo. Esse terreno está situado na porção centro-noroeste da Zona Transversal, a oeste da Zona de Cisalhamento de Boqueirão dos Cochos (que o separa do Terreno Açude Coremas), e imediatamente a sul do Lineamento de Patos. Parte ocidental de suas bordas (e sua delimitação mais ocidental, já no estado do Ceará) está coberta por sedimentos fanerozoicos. 
deve ultrapassar em muito o meridiano 38³0', em razão de se reconhecer e encontrarmos a presença dessas supracrustais neoproterozoicas por sob o extenso capeamento sedimentar mesozoico.

Na constituição do TSJC foram inicialmente destacáveis dois tipos litológicos principais:

- Ortognaisses tonalíticos e metapelitos com algumas intercalações de anfibolitos e calciossilicáticas, e com níveis locais de calcário metamórfico - Unidade "Mp1" no mapa 1/250.000 de Gomes (2000) e/ou Unidade "PP " = "PPp" de Medeiros (2004), que está apenas na porção mais a nordeste do TSJC, ocupando pequena área;

- Paragnaisses e xistos com intercalações de gnaisses tonalíticos, anfibolitos e raras calciossilicatadas, designados "Mp2" no mapa 1/250.000 de Gomes (2000) e chamado de "PPbj" por Medeiros (2004). Essa segunda unidade litoestratigráfica é aquela amplamente predominante (acima de 80\%) em exposição no TSJC. Parte dessa unidade se encontra frequentemente bastante migmatizada.

As designações primeiras (com subtítulos "Mp") partiram de uma suposição de as rochas serem de idade mesoproterozoica - como hipótese primeira de Gomes (2000) — nominalmente (tidas como) pertencentes ao ciclo Cariris Velhos, "Complexo Gravatá", o que veio a ser descartado em nossos estudos. No mapa geológico da Paraíba, Santos et al. (2002) aludiram idade paleoproterozoica ("PgmPY" = "Complexo gnáissico-migmatítico") para os ortognaisses de Piancó e idade mesoneoproterozoica para as rochas dos $\mathrm{PPbj}$, adotando, para esse caso, a designação "Complexo Piancó". A determinação primeira de Kozuch (2003) de rochas paleoproterozoicas e alguns outros dados inéditos foram a razão dessa classificação empregada por esses autores.

Nos estudos que realizamos (campo e microscopia), verificamos uma variedade composicional e litológica muito ampla (Figura 6), tanto de rochas gnáissicas biotíticas (típicos paragnaisses) quanto de ortognaisses (Figura 7A). Em ambos os casos, os processos de migmatização variam de fracos ("estromatíticos" predominantes) para tipos bastante complexos de metatexitos e diatexitos, localmente dominantes (Figura 7B). No momento, optamos por não criar designações, mas os termos preexistentes (PPp e PPbj) não são suficientes para discriminar e abrigar a variedade de litotipos ali encontrada. Só um mapeamento geológico de detalhe poderá demarcar unidades litoestratigráficas mais próximas da realidade de campo (que observamos) e mais adequadas. Além disso, há a variedade introduzida com os processos de migmatização, e de algumas outras rochas modeladas por intenso tectonismo nas bordas, sobretudo, mas também no interior do terreno tectonoestratigráfico em análise. Particularmente, esses contextos litoestratigráficos apresentam porções bastante tectonizadas (nas bordas norte-noroeste e sudeste), perlongando os falhamentos das bordas do terreno.

Por todo esse terreno são inúmeras as intrusões de rochas graníticas, de stocks a batólitos (presença parcial do clássico tipo "Granodiorito Conceição" - "Serra da Lagoinha") relacionados com o arco magmático ediacarano subparalelo (a norte) à Zona Transversal, já mencionado anteriormente (Brito Neves et al., 2016).

O chamado "PPbj" é contexto predominante em área de exposição do TSJC (consoante nessas observações de

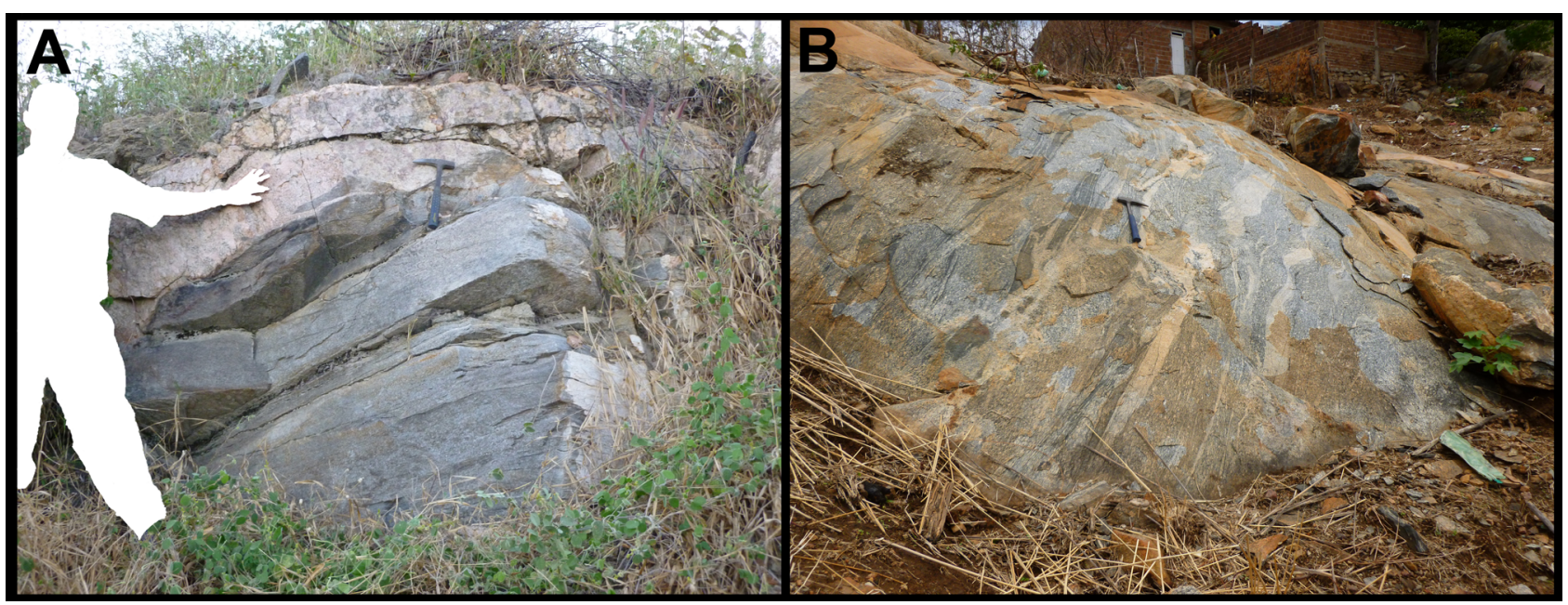

Figura 7. (A) Afloramento em corte de estrada $(5 \mathrm{~km}$ a norte de Bonito, Paraíba - SJCa-9a) de ortognaisses granodioríticos finos, extremamente laminados $\left(\mathrm{S}_{\mathrm{p}} / / \mathrm{S}_{\mathrm{c}}\right.$ ), parcialmente migmatizados. Vide Figura $9 \mathrm{D}$ (idade U-Pb $2212 \pm 13 \mathrm{Ma}$ ); (B) afloramento no centro da cidade de Serra Grande, Paraíba - SJCa-21. Diatexitos e metatexitos, estes com cisalhamento e boudinamento explícitos. Vide Figura 9E (idade U-Pb $2162 \pm 12 \mathrm{Ma}$ ). 
campo), de rochas gnáissicas biotíticas diversas (prováveis paragnaisses) seguidas de ortognáissicas tonalíticas e migmatíticas, com intercalações de anfibolitos e rochas calciossilicatadas. No caso do PPp, este está restrito à pequena área a nordeste do TSJC, bem próximo ao Açude Coremas, onde se destacam rochas ortognáissicas graníticas e tonalíticas, com alguns anfibolitos e rochas calciossilicatadas subordinadas (Figura 6).

A discriminação de idades paleoproterozoicas para essas unidades, em geral, foi expressa pela primeira vez por Santos et al. (2014), baseada em alguns dados ainda inéditos do Centro de Pesquisas em Geocronologia e Geoquímica Isotópica da Universidade de São Paulo (CPGeo-USP) e outros (Kozuch, 2003, de circulação restrita), que serão discutidos apenas no presente trabalho.

Como já reiterado, essas rochas gnáissicas e migmatíticas estão cortadas por inúmeros stocks graníticos, do tipo porfirítico ("tipo Itaporanga", a maioria deles) e de tipos granodioríticos, quartzo dioritos e dioritos (chamados "tipo Conceição"), que são designações corriqueiras em toda a Província Borborema. O limite sudeste do terreno (seu limite com o TAç) é marcado por uma ZC complexa (até $3 \mathrm{~km}$ de largura), de movimento sinistral (Archanjo et al., 1999) e que é responsável por alguns empurrões para sudoeste, gerando cavalgamentos sobre as supracrustais neoproterozoicas
(Supergrupo Santana dos Garrotes, do SPAB), a norte da cidade de Conceição, Paraíba.

\section{Dados isotópicos $\mathrm{Rb}-\mathrm{Sr}$}

Análises pela sistemática $\mathrm{Rb}-\mathrm{Sr}$ foram realizadas em dez amostras (SJCa-1 a SJCa-10) compostas de gnaisses, migmatitos, leucogranitos e ortognaisses do TSJC (Tabela 2). Razões iniciais ${ }^{87} \mathrm{Sr} r{ }^{86} \mathrm{Sr}$ abaixo dos valores do manto primordial $(0,699)$ indicam que houve perda de isótopos de $\mathrm{Sr}$ e/ou ganho de massa de $\mathrm{Rb}$ na maioria das rochas analisadas. Portanto, observou-se claramente que a sistemática isotópica $\mathrm{Rb}-\mathrm{Sr}$ foi fortemente afetada, possivelmente por processo de migmatização em sistema aberto. Dessa forma, corrobora-se que o uso dessa sistemática deve ser feito com ressalvas como método geocronológico e indicador petrogenético por ser sensível a fracionamentos diante de eventos metamórficos. Nota-se que a sistemática $\mathrm{Rb}-\mathrm{Sr}$ durante os eventos metamórficos é afetada facilmente, mas não necessariamente apresenta reomogeneização completa. Assim, tanto as idades quanto os parâmetros petrogenéticos obtidos não apresentam significado geológico em razão de o $\mathrm{Rb}$ e o Sr estarem presentes em minerais sensíveis a transformações (e.g., biotita e feldspatos). Entretanto, foram os primeiros dados paleoproterozoicos desse terreno que nos entusiasmaram

Tabela 2. Dados analíticos das determinações $\mathrm{Rb}-\mathrm{Sr}$ nas rochas do Terreno São José do Caiana.

\begin{tabular}{|c|c|c|c|c|c|c|c|c|c|c|c|c|c|}
\hline Amostra & Rocha & Local & $\begin{array}{c}\text { Coorde- } \\
\text { nadas }\end{array}$ & $\begin{array}{c}\mathrm{Rb} \\
\text { (ppm) }\end{array}$ & $\begin{array}{c}\mathrm{Sr} \\
\text { (ppm) }\end{array}$ & $\begin{array}{l}{ }^{87} \mathrm{Rb} \\
{ }^{186} \mathrm{Sr} \\
\end{array}$ & $\begin{array}{l}{ }^{87} \mathrm{Sr} \\
{ }^{86} \mathrm{Sr}\end{array}$ & $\varepsilon(0)$ & $\begin{array}{r}\mathrm{T}_{\mathrm{DM}} \\
(\mathrm{Ma})\end{array}$ & $\begin{array}{c}\varepsilon \\
\left(T_{D M}\right)\end{array}$ & $\begin{array}{c}\mathrm{T} 1 \\
(\mathrm{Ma})\end{array}$ & $\begin{array}{c}\varepsilon \\
(T 1) \\
\end{array}$ & $\left({ }^{87} \mathrm{Sr} /{ }^{86} \mathrm{Sr}\right)_{\mathrm{i}}$ \\
\hline JCa-1a & Gnaisse & $\begin{array}{c}13 \mathrm{~km} \mathrm{~W} \\
\text { Itaporanga }\end{array}$ & $\begin{array}{l}5835810 \\
9196400\end{array}$ & 309,3 & 14,7 & 63,416 & 1,12751 & $6.004,4$ & 471,0 & $-28,18$ & 2100 & $-21.282,18$ & $-0,79204$ \\
\hline $1 C a-1 \mathrm{~h}$ & Gnais & & $\begin{array}{l}5835810 \\
9196400\end{array}$ & 31,3 & 308,4 & 0,294 & 0,71278 & 117,5 & $2.954,7$ & $-11,70$ & 2100 & 26,36 & ,70388 \\
\hline SJCa-2 & Leucognaisse & $\begin{array}{l}13,2 \mathrm{~km} \mathrm{~W} \\
\text { Itaporanga }\end{array}$ & $\begin{array}{l}5832130 \\
9196520\end{array}$ & 129,1 & 578,6 & 0,646 & 0,71279 & 117,7 & $1.227,8$ & $-23,24$ & 2100 & $-125,24$ & 324 \\
\hline JCa-3 & $\begin{array}{c}\text { Gnaisse } \\
\text { Migmatítico }\end{array}$ & & & 123,7 & 410,1 & 0,875 & 0,73160 & 384,7 & $2.455,9$ & $-15,07$ & 2100 & 43,94 & 0,70511 \\
\hline SJCa-4 & Migmatito & $\begin{array}{l}19,5 \mathrm{~km} \mathrm{~W} \\
\text { Itaporanga }\end{array}$ & $\begin{array}{l}5787130 \\
9198118\end{array}$ & 96,4 & 177,3 & 1,579 & 0,73956 & 497,7 & $1.695,4$ & $-20,15$ & 2100 & $-146,02$ & 78 \\
\hline JCa-5 & Migmatito & $\begin{array}{r}4 \mathrm{kr} \\
\mathrm{S}\end{array}$ & & 89,6 & 226,3 & 1,151 & 0,75068 & 655,5 & $3.027,3$ & $-11,21$ & 2100 & 196,78 & 584 \\
\hline SJCa-6 & Biotita- & $\begin{array}{c}7 \mathrm{~km} \mathrm{~W} \\
\text { SJC }\end{array}$ & $\begin{array}{l}5717600 \\
9196238\end{array}$ & 22,5 & 663,5 & 0,098 & 0,71215 & 108,5 & $12.946,0$ & 62,47 & 2100 & 101,76 & 917 \\
\hline SJCa-7 & anitoide & $\begin{array}{c}12 \mathrm{~km} \mathrm{~W} \\
\mathrm{SJC}\end{array}$ & $\begin{array}{l}567 \\
919\end{array}$ & 233,7 & 191,5 & 3,543 & 0,73926 & 493,4 & 741,1 & $-26,42$ & 2100 & $-997,28$ & 202 \\
\hline SJCa-8 & Ortognaisse & $\begin{array}{c}\text { Sítio } \\
\text { Queixada }\end{array}$ & $\begin{array}{l}5569480 \\
9179338\end{array}$ & 122,0 & 109,5 & 3,250 & 0,78736 & $1.176,2$ & $1.847,2$ & $-19,14$ & 2100 & $-185,73$ & 0,68899 \\
\hline SJCa-9 & $\begin{array}{l}\text { Gnaisse } \\
\text { laminado }\end{array}$ & $\begin{array}{l}4 \text { km N } \\
\text { Bonito, } \\
\text { Paraíba }\end{array}$ & $\begin{array}{l}5541440 \\
9196596\end{array}$ & 76,0 & 584,2 & 0,377 & 0,70979 & 75,1 & $1.594,4$ & $-20,82$ & 2100 & $-51,81$ & 9839 \\
\hline SJCa-10 & $\begin{array}{l}\text { Gnaisse } \\
\text { anfibolítico }\end{array}$ & $\begin{array}{c}20 \text { km N } \\
\text { Bonito, } \\
\text { Paraíba }\end{array}$ & $\begin{array}{l}5848250 \\
9200094\end{array}$ & 169,8 & 968,1 & 0,508 & 0,71035 & 83,1 & $1.226,5$ & $-23,24$ & 2100 & $-100,37$ & 0,69498 \\
\hline
\end{tabular}

SJC: São José do Caiana. 
para o estudo por métodos mais precisos. Eles estão aqui mantidos para facilitar futuros investimentos em pesquisas (foi muito difícil resgatá-los, face ao ineditismo).

\section{Dados isotópicos Sm-Nd}

Pela sistemática $\mathrm{Sm}-\mathrm{Nd}, 15$ amostras foram analisadas nas unidades litoestruturais que compõem o TSJC, cujos resultados analíticos estão presentes na Tabela 3.

O predomínio absoluto dos dados obtidos foi o de determinações com $\mathrm{T}_{\mathrm{DM}}$ apontando idades paleoproterozoicas,
pré-Orosirianas, entre 2,18 e 2,5 Ga, com destaque para três amostras com valores de $\mathrm{T}_{\mathrm{DM}}$ de $2,4 \mathrm{Ga}$ do Sideriano. Os valores fracamente negativos a positivos de $\varepsilon_{\mathrm{Nd}}(\mathrm{t})$ entre -3,08 e 2,41 indicam contribuições de propriedades juvenis com pequena contribuição crustal, em quantidades muito próximas. Amostras de leucogranito, anfibólio-gnaisse, migmatito e ortognaisse (SJCa-7, SJCa-10, SJCa-15 e SJCa-18) apresentaram reomogeneização isotópica do sistema $\mathrm{Sm}-\mathrm{Nd}$ em razão, provavelmente, do evento tectonotermal Brasiliano - destaque azul no gráfico da Figura 8. Essas amostras apresentam idades $\mathrm{T}_{\mathrm{DM}}$

Tabela 3. Dados analíticos das determinações Sm-Nd nas rochas do Terreno São José do Caiana.

\begin{tabular}{|c|c|c|c|c|c|c|c|c|c|c|c|c|c|}
\hline Amostra & Rocha & Local & $\begin{array}{c}\text { Coorde- } \\
\text { nadas }\end{array}$ & $\begin{array}{c}\text { Sm } \\
(p p m)\end{array}$ & $\begin{array}{c}\mathrm{Nd} \\
(\mathrm{ppm})\end{array}$ & $\begin{array}{l}{ }^{147} \mathrm{Sm} / \\
{ }^{144} \mathrm{Nd}\end{array}$ & $\begin{array}{l}{ }^{143} \mathrm{Nd} / \\
{ }^{144} \mathrm{Nd}\end{array}$ & $\varepsilon(0)$ & $\begin{array}{c}\mathrm{F} \\
\mathrm{Sm} / \mathrm{Nd}\end{array}$ & $\begin{array}{r}\mathrm{T}_{\mathrm{DM}} \\
(\mathrm{Ma}) \\
\end{array}$ & $\begin{array}{c}\varepsilon \\
\left(T_{D M}\right)\end{array}$ & $\begin{array}{c}\mathrm{T} 1 \\
(\mathrm{Ma}) \\
\end{array}$ & $\begin{array}{c}\varepsilon \\
(\mathrm{T} 1) \\
\end{array}$ \\
\hline $5 J C-1 a^{*}$ & Gnaisse & $\begin{array}{c}13 \mathrm{~km} W \\
\text { Itaporanga }\end{array}$ & $\begin{array}{l}5835810 \\
9196400\end{array}$ & 2,656 & 10,118 & 0,1587 & 0,511870 & $-14,98$ & $-0,19$ & $2.780,0$ & 2,08 & 2.100 & $-4,83$ \\
\hline$J C-1 b$ & Gnaisse & $\begin{array}{c}13 \mathrm{~km} \mathrm{~W} \\
\text { Itaporanga }\end{array}$ & $\begin{array}{l}5835810 \\
9196400\end{array}$ & 2,006 & 9,641 & 0,1258 & 0,511788 & $-16,58$ & $-0,36$ & $2.181,1$ & 3,14 & 2.100 & 2,41 \\
\hline SJCa-2 & Leucognaisse & $\begin{array}{l}13,2 \mathrm{~km} \mathrm{~W} \\
\text { Itaporanga }\end{array}$ & $\begin{array}{l}5832130 \\
9196520\end{array}$ & 0,279 & 1,374 & 0,1228 & 0,511661 & $-19,06$ & $-0,38$ & $2.325,6$ & 2,87 & 2.100 & 0,74 \\
\hline JCa-3 & $\begin{array}{c}\text { Gnaisse } \\
\text { migmatítico }\end{array}$ & $\begin{array}{c}18 \mathrm{~km} \mathrm{~W} \\
\text { Itaporanga }\end{array}$ & $\begin{array}{l}5796850 \\
9197184\end{array}$ & 6,799 & 42,224 & 0,0974 & 0,511135 & $-29,32$ & $-0,50$ & $2.513,4$ & 2,53 & 2.100 & $-2,71$ \\
\hline $\mathrm{JCa}-4$ & Migmatito & $\begin{array}{l}19,5 \\
\text { Itap }\end{array}$ & $\begin{array}{l}5787130 \\
9198118\end{array}$ & 9,203 & 50,657 & 0,1099 & 0,511402 & $-24,11$ & $-0,44$ & $2.419,8$ & 2,69 & 2.100 & $-0,85$ \\
\hline JCa-5 & Migmatito & $\begin{array}{c}4 \text { km W } \\
\text { São José } \\
\text { do Caiana }\end{array}$ & $\begin{array}{l}5740570 \\
9196090\end{array}$ & 6,604 & 37,78 & 0,1057 & 0,511341 & $-25,30$ & $-0,46$ & $2.412,8$ & 2,71 & 2.100 & $-0,93$ \\
\hline JCa-6 & isse & $\begin{array}{c}7 \text { km W } \\
\text { São José } \\
\text { do Caiana }\end{array}$ & $\begin{array}{l}5717600 \\
9196238\end{array}$ & 1,136 & 5,445 & 0,1262 & 0,511496 & $-22,28$ & $-0,36$ & $2.718,4$ & 2,18 & 2.100 & $-3,38$ \\
\hline $\mathrm{JCa}-7$ & ranito & $\begin{array}{l}12 \text { km W } \\
\text { São José } \\
\text { do Caiana }\end{array}$ & $\begin{array}{l}5676090 \\
9193550\end{array}$ & 8,927 & 64,211 & 0,0841 & 0,511412 & $-23,92$ & $-0,57$ & $1.918,9$ & 3,65 & 600 & $-15,30$ \\
\hline JjCa-8 & Ortognaisse & $\begin{array}{r}\text { S } \\
\text { Que }\end{array}$ & $\begin{array}{l}480 \\
938\end{array}$ & 6,286 & 39,48 & 0,0963 & 0,511211 & -2 & $-0,51$ & $2.387,9$ & 2,75 & 2.100 & $-0,9$ \\
\hline SJCa-9 & Gnaisse & $\begin{array}{l}4 \text { km N } \\
\text { Bonito, } \\
\text { Paraíba }\end{array}$ & $\begin{array}{l}5541440 \\
9196596\end{array}$ & 3,22 & 21,105 & 0,0923 & 0,511046 & $-31,06$ & $-0,53$ & $2.519,9$ & 2,51 & 2.100 & $-3,08$ \\
\hline SJCa- & $\begin{array}{l}\text { Anfibólio- } \\
\text { gnaisse }\end{array}$ & $\begin{array}{c}20 \text { km N } \\
\text { Bonito, } \\
\text { Paraíba }\end{array}$ & & 13,874 & 102,68 & 0,0817 & 0,511315 & $-25,81$ & $-0,58$ & $1.997,6$ & 3,49 & 600 & $-17,01$ \\
\hline $96-282$ & Gna & $\begin{array}{c}2 \text { km S } \\
\text { São José } \\
\text { do Caiana }\end{array}$ & $\begin{array}{l}270 \\
551\end{array}$ & 6,31 & 43,84 & 0,0870 & 0,511062 & $-30,74$ & $-0,56$ & $2.393,5$ & 2,74 & 2.100 & $-1,37$ \\
\hline SJCa-15 & Migmatítico & $\begin{array}{c}19 \mathrm{~km} \mathrm{~W} \\
\text { Itaporanga }\end{array}$ & $\begin{array}{l}30 \\
84\end{array}$ & 6,675 & 44,745 & 0,0902 & 0,511540 & $-21,42$ & $-0,54$ & $1.855,4$ & 3,78 & 600 & $-13,27$ \\
\hline SJCa-16 & Migmatito & $\begin{array}{l}\text { Capim } \\
\text { Verde }\end{array}$ & $\begin{array}{l}5734520 \\
9201472\end{array}$ & 3,414 & 21,589 & 0,0956 & 0,511190 & $-28,25$ & $-0,51$ & $2.402,1$ & 2,72 & 2.100 & $-1,17$ \\
\hline SJCa-18 & Ortognaisse & $\begin{array}{l}\text { Monte } \\
\text { Orebe }\end{array}$ & $\begin{array}{l}70 \\
90\end{array}$ & 6,378 & 49,557 & 0,0778 & 0,511289 & 31 & $-0,60$ & $1.969,5$ & 3,55 & 600 & $-17,22$ \\
\hline SJCa-19 & $\begin{array}{l}\text { Augen- } \\
\text { gnaisse }\end{array}$ & $\begin{array}{l}\text { Sul Mata } \\
\text { Grande }\end{array}$ & $\begin{array}{l}5569340 \\
9179938\end{array}$ & 5,487 & 36,519 & 0,0909 & 0,511132 & $-29,38$ & $-0,54$ & $2.380,6$ & 2,76 & 2.100 & $-1,03$ \\
\hline SJCa-10 & $\begin{array}{l}\text { Anfibólio- } \\
\text { gnaisse }\end{array}$ & $\begin{array}{c}20 \mathrm{~km} \mathrm{~N} \\
\text { Bonito, } \\
\text { Paraíba }\end{array}$ & $\begin{array}{l}5488250 \\
9200094\end{array}$ & 13,874 & 102,68 & 0,0817 & 0,511315 & $-25,81$ & $-0,58$ & $1.997,6$ & 3,49 & 600 & $-17,01$ \\
\hline
\end{tabular}

SJC: São José do Caiana; *cálculo por duplo estágio. 


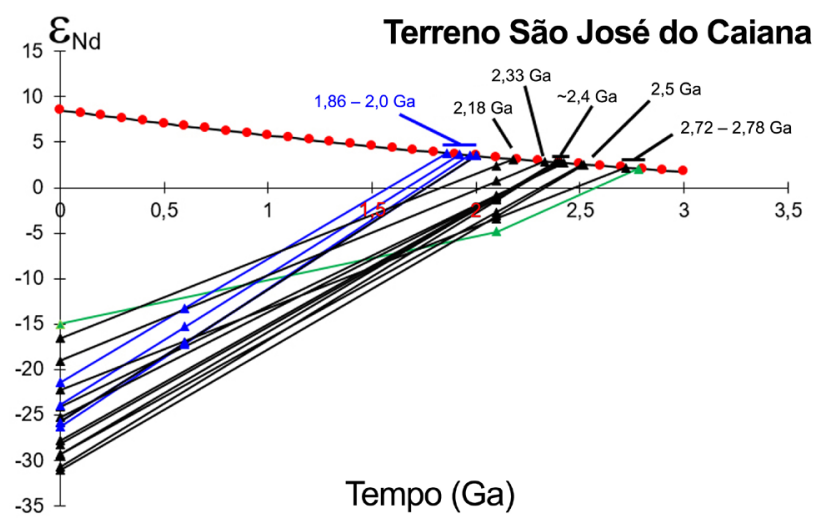

Figura 8. Diagrama de evolução isotópica do $\mathrm{Nd}$ das amostras do Terreno São José do Caiana (discussão no texto).

bem mais jovens e distintas das demais, entre 1,8 e 2,0 Ga, bem como valores de $\varepsilon_{\mathrm{Nd}}(\mathrm{t})$ bastante negativos, entre -13 e -17 , indicando significativa residência prévia e contribuição crustal nesse evento.

Apenas duas amostras apresentaram seus protólitos diferenciados do manto no Neoarqueano, com valores de $\mathrm{T}_{\mathrm{DM}}$ entre 2,72 e 2,78 Ga e valores fracamente negativos de $\varepsilon_{\mathrm{Nd}}(\mathrm{t})$ muito próximos $(-4,83$ e $-3,38)$. Uma delas, um gnaisse granítico (SJCa-1a), apresentou fracionamento adicional entre $\mathrm{Sm}$ e $\mathrm{Nd}$, e o modelo de evolução de isótopos de $\mathrm{Nd}$ em duplo estágio foi utilizado para o cálculo do $\mathrm{T}_{\mathrm{DM}}$ (DePaolo et al., 1991), destacado no gráfico da Figura 8.

Assim, no gráfico de evolução do $\mathrm{Nd}$ se destacam três agrupamentos distintos no TSJC: o primeiro grupo com valores de $T_{D M}$ orosirianos e de $\varepsilon_{\mathrm{Nd}}(t)$ bastante negativos (amostras SJCa-7, SJCa-10, SJCa-15 e SJCa-18); o segundo grupo com valores de $T_{D M}$ neoarqueanos e de $\varepsilon_{\mathrm{Nd}}(\mathrm{t})$ fracamente negativos (amostras SJCa-1a e SJCa-6); e o terceiro grupo com valores de $T_{D M}$ pré-orosirianos e de $\varepsilon_{N d}(t)$ fracamente negativos a positivos (demais amostras).

No presente estudo, podemos especular que as separações manto-crosta se processaram em momentos distintos, consoante a composição de componentes relativamente diferentes (mais máficos e, depois, mais félsicos) para a formação do TSJC. O retrabalhamento desses materiais/rochas colocadas na crosta (advindos do manto) foi intenso, de muitas formas e delongado, a partir do Orosiriano até o Neoediacarano.

\section{Determinações U-Pb}

Determinações U-Pb em zircão foram realizadas em cinco amostras (Documento Suplementar - Tabela 2), e assim procuramos cobrir vários rincões do TSJC, geralmente em rochas epigrafadas, como as do PPbj que, como já discutimos, inclui uma gama muito variada de paragnaisses, ortognaisses e migmatitos. As amostras datadas representantes do embasamento - basement inliers - são compostas de biotita-gnaisses, metagranodioritos, ortognaisses (amostra SJCa-9a - Figura 7A) e migmatitos (amostra SJCa-21 - Figura 7B). A amostra SJCa-1 (Figura 9A) representa um ortognaisse localizado a $13 \mathrm{~km} \mathrm{~W}$ de Itaporanga no sentido de Conceição, Paraíba (coordenadas 9196262 - 583411). O leucognaisse (amostra SJCa-3a — Figura 9B) está localizado a $18 \mathrm{~km} \mathrm{~W}$ de Itaporanga, Paraíba (coordenadas 9196926 - 580705). A amostra SJCa-5a (Figura 9C) representa um gnaisse migmatítico situado a $4 \mathrm{~km} \mathrm{~W}$ de São José do Caiana, Paraíba (coordenadas 9196238 - 57175). A amostra SJCa-9a (Figura 9D) foi coletada onde afloram gnaisses granodioríticos laminados (protomiloníticos), a $4 \mathrm{~km}$ a norte de Bonito, Paraíba (coordenadas 9196600 - 554144). A amostra SJCa-21 (Figura 9E) é constituída de um ortognaisse migmatizado no centro da cidade de Serra Grande, a leste de São José do Caiana (coordenadas 9166600 - 554144).

\section{Discussão dos dados U-Pb - Terreno São José do Caiana}

As amostras SJCa-1, SJCa-3a, SJCa-9a e SJCa-21 apresentaram valores de idades próximas, do Riaciano (entre 2136 e 2209 Ma, com pequenos erros), e valores e Mean Square Weighted Deviation (MSWD) geralmente baixos (Figura 9), dados que as caracterizam como de boa qualidade analítica em geral, dignas de crédito. Todas as amostras apresentam perda contínua de $\mathrm{Pb}$, e apesar de erros elevados, mostram interceptos inferiores (ou tendência de idade) para o Neoproterozoico, evidenciando a sobreposição dos eventos do Ciclo Brasiliano em todas essas rochas amostradas.

A amostra SJCa-5a se difere das amostras anteriormente discutidas, pois apresenta um grupo de zircões com idade do Sideriano Superior (2326 $\pm 12 \mathrm{Ma})$ e um segundo grupo de zircões que indica idade do Riaciano (ca. $2200 \pm 40 \mathrm{Ma}$ ), grupo este semelhante às quatro amostras discutidas anteriormente (Figura 9C). A análise das imagens de catodoluminescência indica que as idades siderianas foram obtidas em núcleos antigos (inherited cores), que, por sua vez, apresentam bordas com zoneamento oscilatório magmático de idade riaciana (Figura 10). Assim, supõe-se que essa amostra de idade paleoproterozoica registra um retrabalhamento crustal de rochas siderianas da Província Borborema, provavelmente referente a processos tafrogenéticos. Esse dado é corroborado pela sistemática $\mathrm{Sm}-\mathrm{Nd}$, que mostrou valor de $\mathrm{T}_{\mathrm{DM}}$ sideriano, porém valor de $\varepsilon_{\mathrm{Nd}}(\mathrm{t})$ fracamente negativo, implicando pouca contribuição crustal. 


\section{Terreno São José do Caiana}
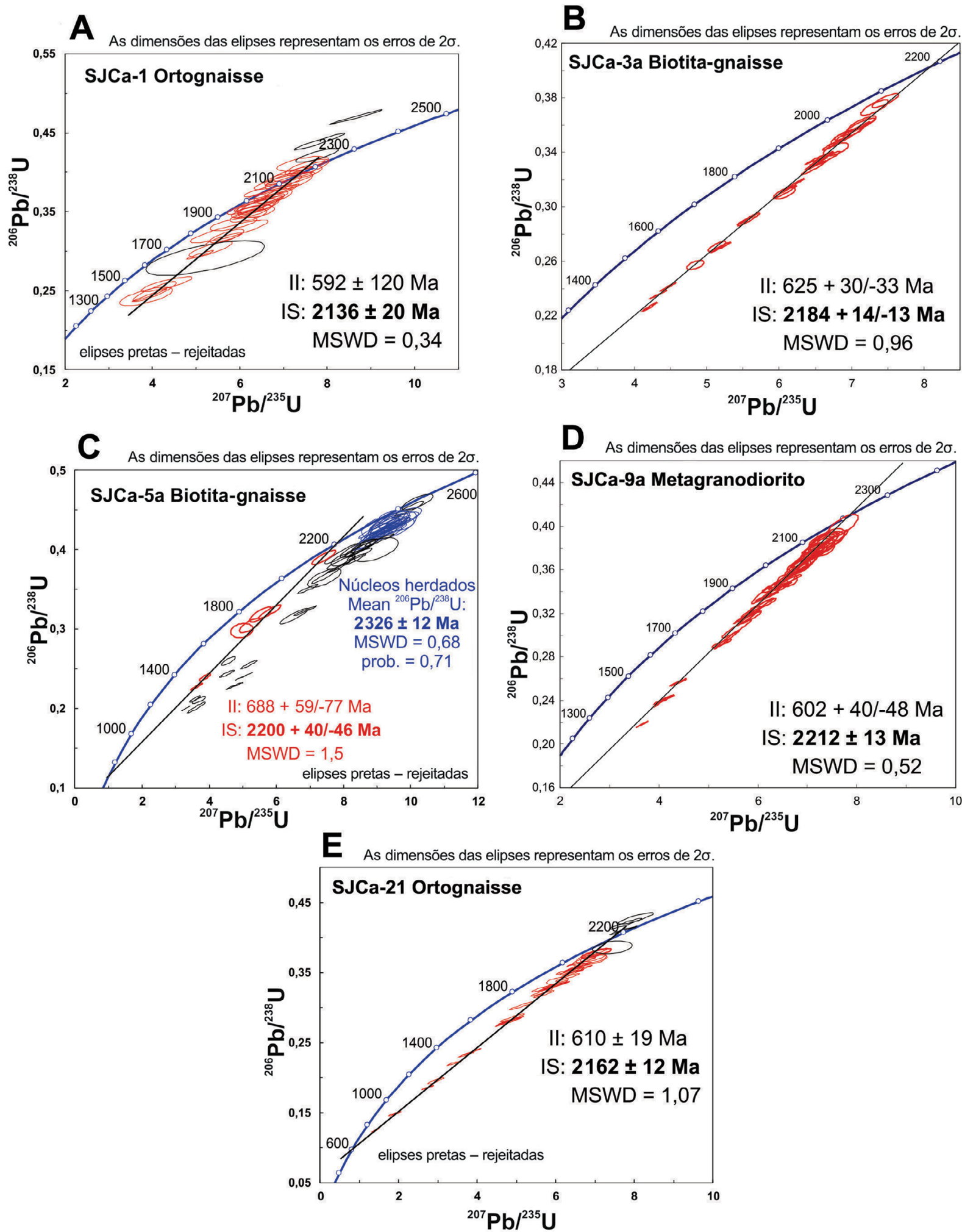

II: intercepto inferior; IS: intercepto superior; MSWD: mean square weighted deviation.

Figura 9. Diagramas Concórdia (U-Pb em zircões) para gnaisses e metagranitoides do Terreno São José do Caiana (discussão no texto). 


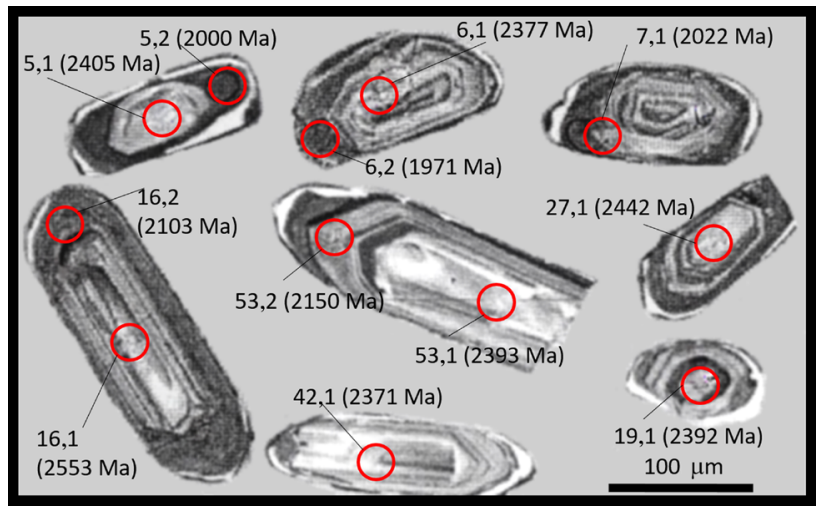

Figura 10. Imagens de catodoluminescência em cristais de zircão da amostra SJCa-5a. Spots e respectivas idades ${ }^{206} \mathrm{~Pb} /{ }^{238} \mathrm{U}$ estão assinalados.

\section{O TERRENO ICAIÇARA, A OESTE DA ZONA TRANSVERSAL}

No oeste de Pernambuco, separando duas faixas de dobramentos neoproterozoicas (Ouricuri-Bodocó, a oeste, e Salgueiro-Verdejante, a leste) que são partes do SPAB e situado entre duas importantes ZCs (Trempe, a oeste, e Parnamirim, a leste), está localizado o inlier de embasamento que recebeu a designação “Icaiçara" - TIc (Santos, 1996; Santos et al., 1997), o que é reiterado e discutido no presente trabalho. No trabalho de Lages e Dantas (2016), mais recente, o TIc está mapeado como composto de gnaisses e migmatitos de composição granodiorítica, com ênfase para augen-gnaisses grossos (quartzo sieníticos e monzograníticos). Existe uma unidade superior de capa, composto de biotita-gnaisse bastante bandado (e até rítmico) na parte central do terreno, que foi chamada de "Complexo Barro", em trabalho anterior de Cruz et al. (2012).

Esse componente mais superior do embasamento - mas que já acoberta um substrato mais antigo preexistente — fora mapeado pelo trabalho do Centro de Tecnologia e Geociências da Universidade Federal de Pernambuco/Departamento Nacional da Produção Mineral (CTG-UFPE/DNPM, 1983), sem designação formal ("Cx", apenas), em escala 1/100.000, com expressão territorial mais ramificada, e equiparado de pronto com o que atualmente se chama Supergrupo Salgueiro (também, naquela oportunidade, designado informalmente de "Cx"), da faixa Parnamirim-Verdejante (essencialmente por características litológicas), situada a leste da folha Icaiçara, a norte e a leste do TIc. Geralmente, balizando todo o contexto do TIc, consoante falhamentos importantes (transcorrentes e transpressionais), encontram-se rochas do Supergrupo Santana dos Garrotes, do SPAB.

Esse terreno de direção geral NE-SW apresenta forma de quadrilátero bastante irregular (55 km de comprimento SW-NE, 35 km de largura NW-SE — Figura 11). A sul, é bordejado e arrastado de forma destral pelo Lineamento de Pernambuco. No interior desse quadrilátero irregular, a foliação se encontra sinuosamente dobrada, descrevendo tracejado de um padrão de interferência de estruturas praticamente perpendiculares entre si (tipo "caixa de ovos"). O TIc tem história estrutural complexa, sendo seus limites importantes zonas de falhas, como já mencionado: a oeste, falha do Trempe; a leste, falha de Parnamirim (ambas NNE-SSW); a sul, Lineamento Pernambuco. Além de ter sido penetrado por muitos plutões graníticos (tipo "Serrita"), alguns de tendência trondhjemítica. Têm sido mencionados rochas monzograníticas, monzodioríticas e biotita granitos intrusivos e, entre estes, aqueles de afinidade trondhjemítica - parte do Arco Magmático ediacarano descrito por Brito Neves et al. (2016).

O TIc é composto essencialmente de rochas gnáissicas (augen-gnaisses comuns) de composição quartzo-sienítica a monzonítica (ortoderivados) e gnaisses bandados parcialmente migmatizados, consoante mapeamentos regionais de Cruz et al. (2012), Lages e Dantas, (2016) e CTG-UFPE/DNPM (1983), que foram compilados e estão integrados na Figura 11.

Como mencionado, a ZC a oeste, Trempe, apresenta rejeito destral com um componente de empurrão de rochas do SPAB por sobre os gnaisses do TIc. Essa falha (NNE-SSW, ca. $130 \mathrm{~km}$ ) é bruscamente arrastada a sul pelo Lineamento Pernambuco, do qual se comporta como uma feather fault. Essa ZC separa o TIc do ramo aulacogênico Ouricuri-Bodocó (do SPAB), que fica a oeste, composto de metassedimentos (pelíticos, psamo-pelíticos) de baixo grau.

A ZC de Parnamirim apresenta rejeito sinistral e vai do Lineamento Pernambuco (onde se enraíza), a sul, até, pelo menos, Jati, no Ceará, e marca o limite oriental do terreno (com as supracrustais do SPAB). Essa ZC (>90 km de comprimento, no mínimo observável) marca o limite oriental do terreno para com as supracrustais do ramo/faixa Parnamirim-Verdejante, de médio a baixo grau (metapelitos, metapsamitos, metaturbiditos, com muitas intercalações vulcânicas, pertencentes ao SPAB). Há também evidências de movimentos transpressionais, associados com o rejeito direcional, jogando as rochas do SPAB (Supergrupo Salgueiro) sobre o TIc.

\section{Composição e estrutura}

O esqueleto central e principal do TIc é formado por augen-gnaisses a biotita, de composição calcioalcalina a alcalina (metaquartzo-sieníticos, metamonzograníticos), geralmente apresentando textura muito grossa, com fácies locais microporfiríticas. Trata-se do contexto mais expressivo em área do TIc, que chama muito a atenção pela sua fisiografia (relevo granítico), pelo solo arenoso e pelos afloramentos muito especiais (para observação de composição e estruturas), chamado informalmente de "Fragmento de Icaiçara". A Figura 12A mostra o afloramento de ortognaisse granítico a quartzo 


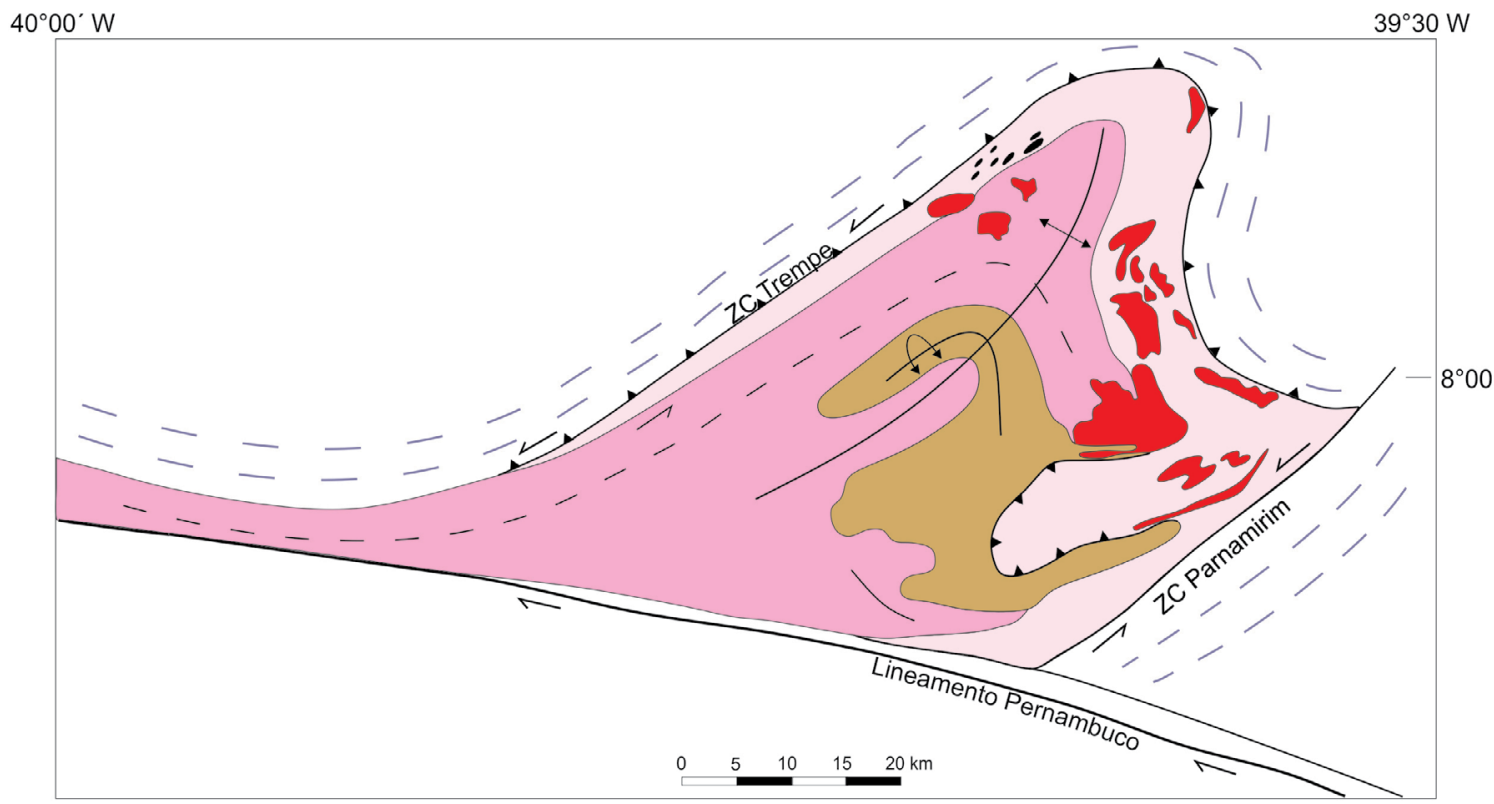

Granitoides diversos

Granada-biotita-gnaisses - intercalações de mármores e BIFS "Complexo Barro"

$\because$ Lentes máfica-ultramáficas retroeclogíticas (ocorrências $\mathrm{Fe}, \mathrm{Ti}, \mathrm{Cl} \pm \mathrm{Cu}$ )

- Xistos de médio a baixo grau

Faixas Ouricuri e Parnamirim-Verdejante

Metaquartzo-sienitos, biotita-augen-gnaisses

Fontes: Lages e Dantas (2016)

"Fragmento Icaiçara" Beurlen et al. (1992)

Orto e paragnaisses diversos

"Complexo Parnamirim"

ZC: zona de cisalhamento.

Figura 11. Esquema geológico do Terreno Icaiçara, entre os paralelos 39³0' e 4000', na porção oeste da Zona Transversal, no interior (noroeste) do estado de Pernambuco. A colocação tectônica e a composição litoestrutural expressas na legenda são discutidas no texto.
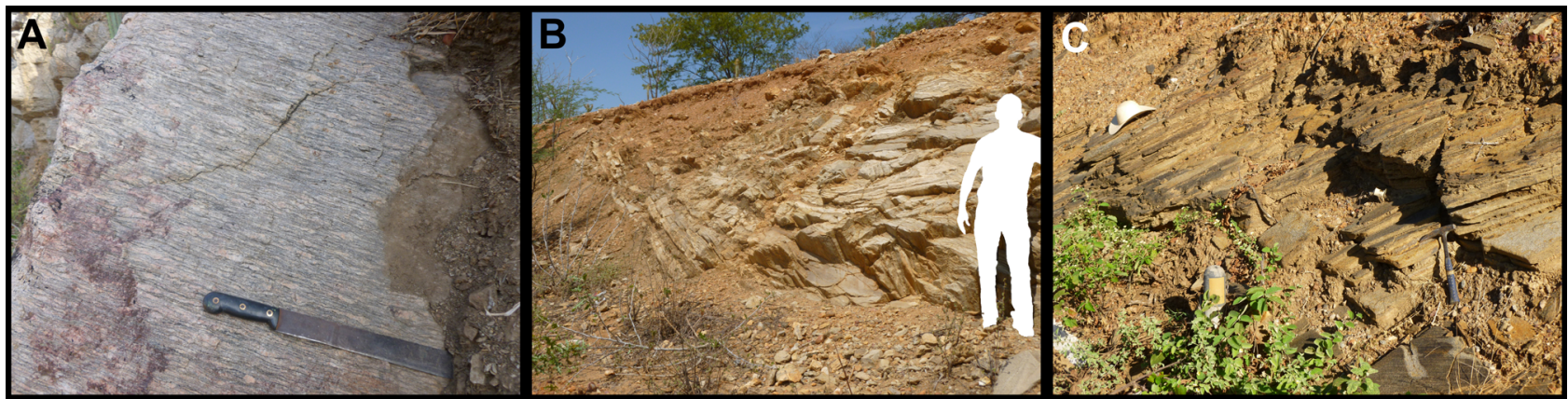

Figura 12. (A) Ortognaisses do chamado "Fragmento de Icaiçara", amostra PAPE-205; (B) gnaisses de Paramirim, afloramento PAPE-20; (C) metarritmitos (metapsamo-pelitos) de médio a baixo grau do "Complexo Barro".

sienítico (amostra PAPE-205), de idade paleoproterozoica (vide idade U-Pb - Figura 14B), predominante na porção central do TIc (Figura 11). A textura protomilonítica permite a observação de vários indicadores cinemáticos, indicando, no caso, movimentação tectônica de sudoeste para nordeste.
Foi nesse contexto em que foi primeiramente obtida uma determinação geocronológica paleoproterozoica $\mathrm{Pb} / \mathrm{Pb}$ de $1969 \pm 9 \mathrm{Ma}$ - dados inéditos do Prof. Jardim de Sá, por nós auferidos. Esse contexto ortoderivado é contornado (pelas bordas do TIc) por uma série de rochas gnáissicas (com a 


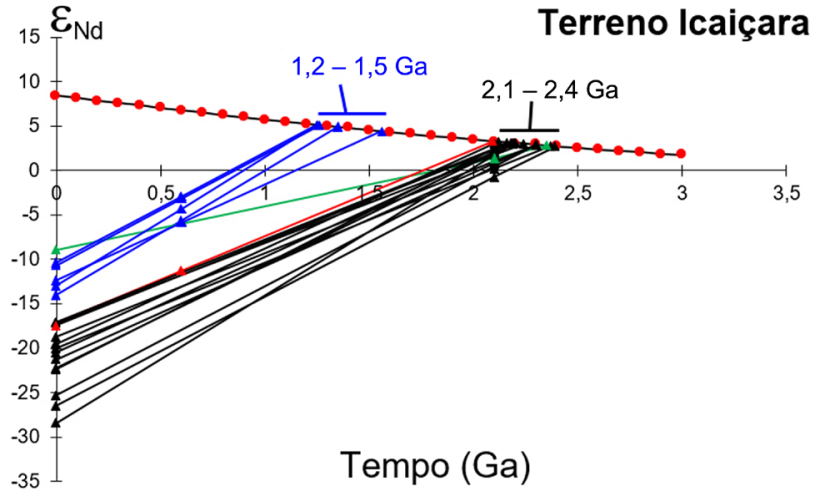

Figura 13. Diagrama de evolução isotópica do Nd para as rochas do Terreno Icaiçara (discussão no texto).

qual mostra frequentes interdigitações), muito variadas em composição, ortoderivadas (graníticas, granodioríticas) e paraderivadas (muscovita gnaisses), metagranitos tipo $\mathrm{S}$, localmente com algumas intercalações de rochas metamáficas e metaultramáficas. Trata-se do que foi chamado de "Complexo Parnamirim" (Figura 12B), que por ser localizado nas bordas oeste e leste do TIc (Figura 11), foi extremamente tectonizado ao curso das ações das ZCs Trempe e Parnamirim. Em corte rodoviário nas imediações da cidade topônima dos "gnaisses de Paramirim" (afloramento PAPE-20 - Figura 12B) ocorrem paragnaisses e ortognaisses extremamente bandados que contornam praticamente a área poligonal do TIc (vide idade U-Pb - Figura14A).

Encaixadas no interior dessas rochas gnáissicas, há algumas ocorrências de rochas máficas e ultramáficas, de afinidades retroeclogíticas e mineralizações de Fe-Ti (Beurlen et al., 1992; Lages e Dantas, 2016). Dados geocronológicos nessas unidades são necessários (para comprovar ou não a ligação com a zona de subducção do Brasiliano), mas esse tem sido um problema de difícil solução por falta de minerais radioativos apropriados nessas rochas máfico-ultramáficas.

O "Complexo Barro", que aparece recobrindo os contextos anteriores, é principalmente constituído de gnaisses micáceos e granadíferos, granada xistos rítmicos, localmente migmatizados - por vezes, extremamente bandados (Figura 12C), lembrando metaritmitos. Em corte de estrada na BR-232, próximo a Quixaba, ocorrem metaritmitos (metapsamo-pelitos) de médio a baixo grau do Complexo Barro (Figura 12C). Essa unidade está em uma estruturação de aloctonia (nappismo) sobre as demais unidades. Ela está indicando idade neoproterozoica pelos seus zircões detríticos (vide idade U-Pb - Figura 15). Em trabalhos (inéditos) anteriores, de 1983, do Centro de Tecnologia e Geociências (CTG-UFPE), essa posição de aloctonia já havia sido registrada e cartografada. Como esse trabalho não foi publicado devidamente, essa proposta de aloctonia permaneceu obscura.
Algumas intercalações de rochas calciossilicatadas e mármores são conhecidas. Trata-se de um contexto difícil de demarcar cartograficamente e estabelecer relações litoestratigráficas com a segurança necessária. No nosso levantamento geocronológico, dispondo dos mapas de Cruz et al. (2012; escala 1/100.000) e de Lages e Dantas (2016; com síntese na escala 1/500.000), conseguimos estabelecer (sem cartografia adequada almejada) e distinguir um contexto mais jovem, pós-Mesoproterozoico, com muitas semelhanças (até mesmo geocronológicas) com o que havíamos obtido no "Supergrupo Salgueiro", na faixa de dobramento oriental ao TIc, pertencente ao SPAB (Brito Neves e Campos Neto, 2016). Esse contexto de idades mais jovens foi consignado em amostras a leste da localidade de Quixaba e nas proximidades de vila Icaiçara (que tentamos reproduzir no esquema da Figura 11).

É justo acrescentar aqui que no mapa do Projeto Extremo Oeste de Pernambuco (CTG-UFPE/DNPM, 1983), em escala 1/100.000, de circulação extremamente restrita (jamais publicado), foi feita uma discriminação cartográfica de uma unidade mais velha, "granada muscovita gnaisses" (Bgn), com intercalações quartzíticas e anfibolíticas (os ortognaisses e os paragnaisses dos embasamentos Icaiçara e Parnamirim, e de uma unidade mais jovem, "xistos, biotita xistos, intercalações calciossilicáticas e corpos lentiformes de mármore", apelidadada de "Cx"). Como as litologias de Bgn (parte de) e Cx são muito próximas (em escala de campo), entendemos por que essa subdivisão não apareceu nos mapeamentos posteriores. Essa unidade Cx correspondia (nesse mapa inédito) ao que foi chamado, posteriormente, de "Complexo Barro" e, em grande parte, ao "Supergrupo Salgueiro" (situado mais a leste), ramo sul do SPAB.

A separação do Complexo Barro ou Cx (ou Salgueiro) das demais unidades do embasamento do TIc é um fato observável no campo, mas necessita de uma cartografia geológica mais refinada. Como verificamos em campo, a cartografia tem alguns problemas, e isso tem repercussão imediata no trato com os dados geocronológicos.

Do ponto de vista estrutural, o TIc apresenta um comportamento bastante interessante, traduzido em lineações (subparalelas às margens do terreno) compondo em conjunto um padrão de interferência muito complexo de deformações perpendiculares entre si, como já mencionado. As estruturas predominantes (mais antigas, $\mathrm{S}_{\mathrm{p}}$ ) são posicionadas na direção N-NE, e estão sendo entrecortadas por estruturas sobrepostas $\mathrm{NW}-\mathrm{SE}\left(\mathrm{S}_{\mathrm{p}+1}\right)$. Estão sobrepostos a esse padrão complexo geral observado os movimentos transpressionais das ZCs Trempe (a oeste) e Parnamirim (a leste). Associado a esta, podemos identificar frações importantes do "Supergrupo Salgueiro", do SPAB, jogado por sobre o embasamento do TIc. Duas superfícies de franco empurrão podem ser detectadas: no bordo leste, na Fazenda Alexandria (NE-SW), mais próxima da ZC Parnamirim, e de Quixaba-Icaiçara (NNESSW), na parte mais central do TIc. 


\section{Terreno Icaiçara}
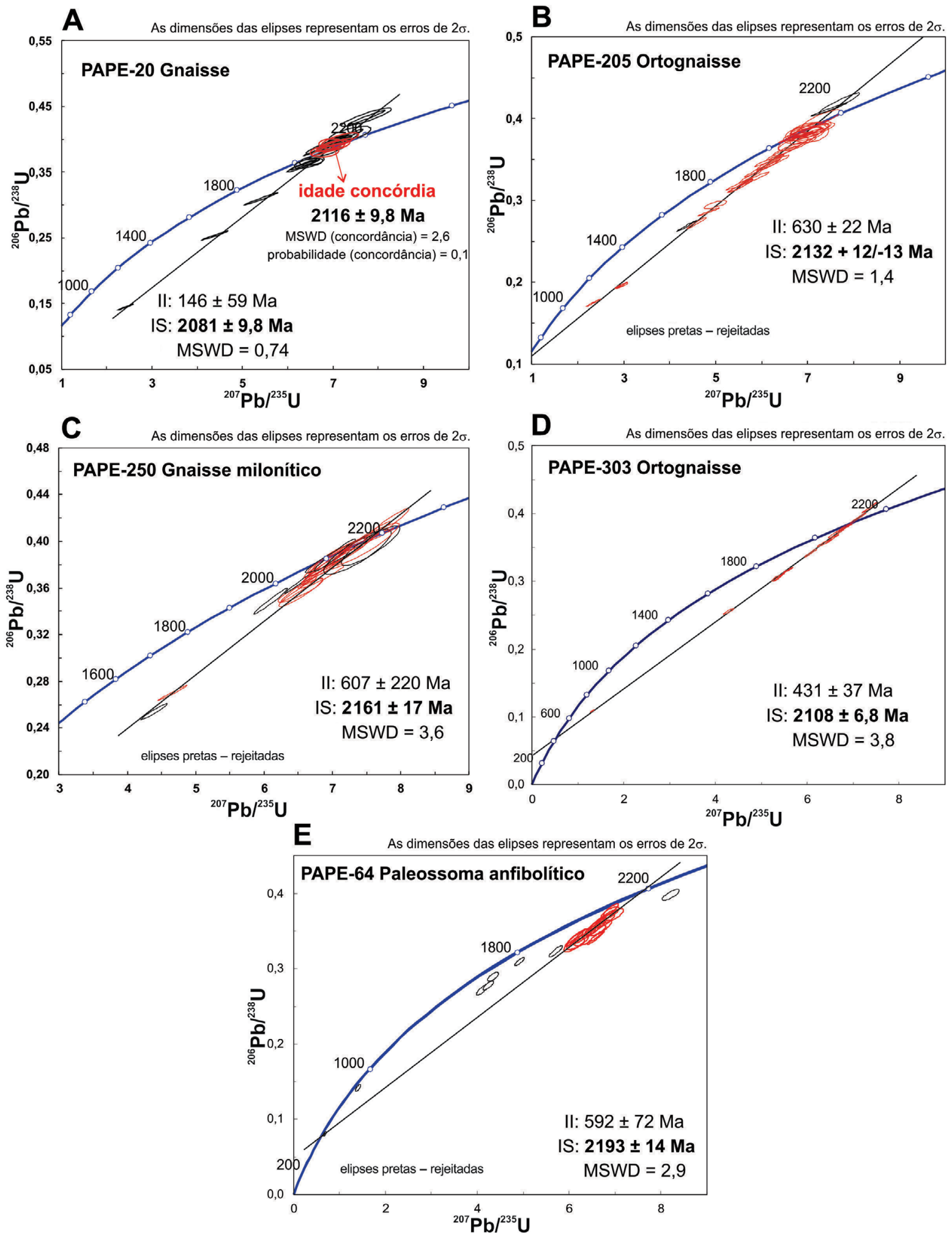

II: intercepto inferior; IS: intercepto superior; MSWD: mean square weighted deviation.

Figura 14. Diagramas Concórdia (U-Pb em zircões) para gnaisses e migmatitos do Terreno Icaiçara. (A) Amostra PAPE-20; (B) amostra PAPE-205; (C) amostra PAPE-250; (D) amostra PAPE-303; (E) amostra PAPE-64 (discussão no texto). 


\section{Terreno Icaiçara - Complexo Barro}
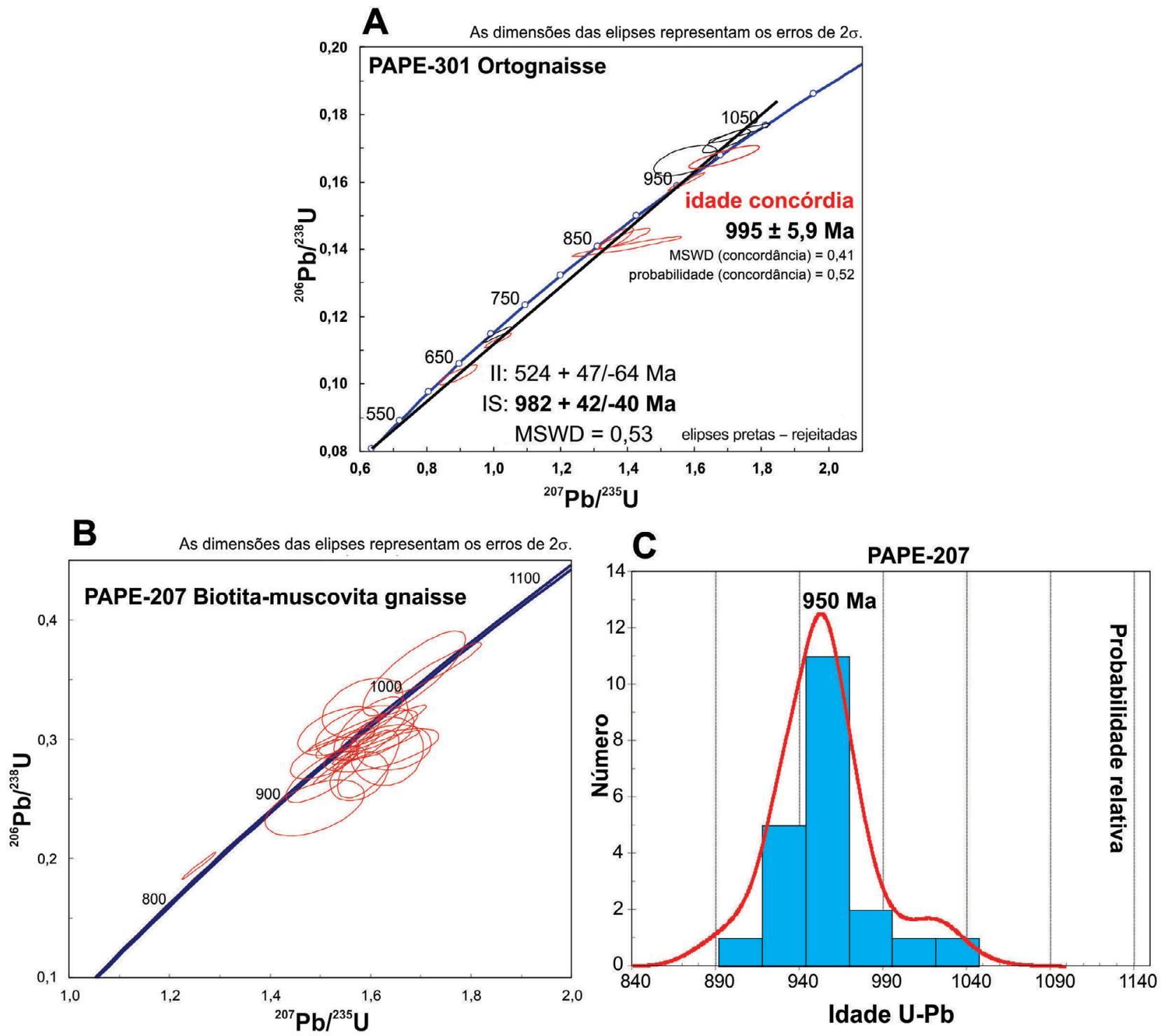

II: intercepto inferior; IS: intercepto superior; MSWD: mean square weighted deviation.

Figura 15. Datações U-Pb em zircão para rochas gnáissicas do Complexo Barro. (A) Diagrama Concórdia U-Pb em zircões de ortognaisse granítico fino (amostra PAPE-301); (B) amostra PAPE-207; (C) histograma de probabilidade relativa dos zircões detríticos amostrados no paragnaisse (amostra PAPE-207), plotados somente spots com 100 +/- 10\% de concordância. Discussão no texto.

\section{Dados isotópicos $\mathrm{Rb}-\mathrm{Sr}$}

Análises pela sistemática $\mathrm{Rb}-\mathrm{Sr}$ foram realizadas em sete amostras compostas de gnaisses, migmatitos e ortognaisses do TIc (Tabela 4). Igualmente como observado nas rochas analisadas do TSJC, foram obtidas razões iniciais ${ }^{87} \mathrm{Sr} /{ }^{86} \mathrm{Sr}$ abaixo dos valores do manto primordial $(0,699)$, com indicação de perda de massa de $\mathrm{Sr}$ e/ou ganho de massa de
$\mathrm{Rb}$ na maioria das rochas analisadas. Portanto, conforme discutido anteriormente, observou-se que a sistemática isotópica $\mathrm{Rb}-\mathrm{Sr}$ foi fortemente afetada, no entanto sem ter sofrido reomogeneização isotópica completa. Assim, as idades e os parâmetros petrogenéticos obtidos não apresentam significado geológico claro. A Tabela 4 foi elaborada e é apresentada neste trabalho por razões históricas, tendo em vista que esses dados jamais foram publicados, e foi com 
Tabela 4. Dados analíticos das determinações $\mathrm{Rb}-\mathrm{Sr}$ nas rochas do Terreno Icaiçara.

\begin{tabular}{|c|c|c|c|c|c|c|c|c|c|c|c|c|c|}
\hline Amostra & Rocha & Local & $\begin{array}{c}\text { Coorde- } \\
\text { nadas }\end{array}$ & $\begin{array}{c}\mathrm{Rb} \\
(\mathrm{ppm})\end{array}$ & $\begin{array}{c}\mathrm{Sr} \\
(\mathrm{ppm})\end{array}$ & $\begin{array}{c}{ }^{87} \mathrm{Rb} / \\
{ }^{86} \mathrm{Sr}\end{array}$ & $\begin{array}{l}{ }^{87} \mathrm{Sr} / \\
{ }^{86} \mathrm{Sr}\end{array}$ & $\varepsilon(0)$ & $\mathrm{T}_{\mathrm{DM}}(\mathrm{Ma})$ & $\begin{array}{c}\varepsilon \\
\left(\mathrm{T}_{\mathrm{DM}}\right)\end{array}$ & $\begin{array}{c}\mathrm{T} 1 \\
(\mathrm{Ma}) \\
\end{array}$ & $\begin{array}{c}\varepsilon \\
(\mathrm{T} 1) \\
\end{array}$ & $\left({ }^{87} \mathrm{Sr} /{ }^{86} \mathrm{Sr}\right)_{\mathrm{i}}$ \\
\hline PAPE-53 & $\begin{array}{l}\text { Cx gnáissico } \\
\text { migmatítico }\end{array}$ & $\begin{array}{l}31 \mathrm{~km} \mathrm{SE} \\
\text { Ouricuri }\end{array}$ & $\begin{array}{l}9116344 \\
4102670\end{array}$ & 68,1 & 46,9 & 4,217 & 0,74310 & 547,9 & 686,0 & $-26,78$ & 2.100 & $-1.233,27$ & 0,61545 \\
\hline APE-111 & Ortognaisse & $\begin{array}{c}\text { Barro, } \\
\text { Pernambuco }\end{array}$ & $\begin{array}{l}9113104 \\
4178280\end{array}$ & 132,3 & 204,6 & 1,879 & 0,74852 & 624,9 & & $-19,74$ & 2.100 & $-147,89$ & 165 \\
\hline VM-34B & Gnaisse & BR-232 & & 74,0 & 147,0 & 1,464 & 0,75718 & 747,8 & & $-13,56$ & 2.100 & 154,34 & 286 \\
\hline $5 \mathrm{~B}$ & Gnaisse & BR-232 & $\begin{array}{l}9117400 \\
4076000\end{array}$ & 52,0 & 62,0 & 2,441 & 0,76283 & 828,0 & & $-19,72$ & 2.100 & $-186,22$ & 896 \\
\hline VM- & naisse & BR-232 & $\begin{array}{l}9117400 \\
4076000\end{array}$ & 71,0 & 173,0 & 1,192 & 0,74655 & 596,9 & 5,0 & $-13,59$ & 2.100 & 120,07 & 046 \\
\hline VM-47 & Gnaisse & BR-232 & $\begin{array}{l}9108000 \\
4290000\end{array}$ & 115,0 & 121,0 & 2,767 & 0,76657 & 881,1 & $1.646,3$ & $-20,47$ & 2.100 & $-273,54$ & 0,68283 \\
\hline VM-49B & Gnaisse & BR-232 & $\begin{array}{l}9116600 \\
4312000 \\
\end{array}$ & 128,0 & 111,0 & 3,366 & 0,79408 & 1271,5 & $1.922,4$ & $-18,64$ & 2.100 & $-140,04$ & 0,69220 \\
\hline
\end{tabular}

cx.: complexo.

certo trabalho extra (e custoso, como foi no nosso caso) que pudemos resgatá-los.

\section{Dados isotópicos Sm-Nd}

Pela sistemática Sm-Nd, 20 amostras foram analisadas nas unidades litoestruturais que compõem o TIc, cujos resultados analíticos estão apresentados na Tabela 5. Dois grupos distintos são francamente observados no diagrama de evolução isotópica do Nd (Figura 13).

O primeiro grupo (à esquerda do diagrama) está representado por amostras do Complexo Barro, fração de uma nappe brasiliana, em que se sobrepõem os gnaisses e os migmatitos paleoproterozoicos do Icaiçara (amostras PAPE-111, PAPE-123, PAPE-207B e PAPE-207G). Apresentam $T_{D M}$ de idades mesoproterozoicas, na maioria ectasianas (entre 1,25 e $1,35 \mathrm{Ga}$ ), e uma amostra de biotita-gnaisse com $\mathrm{T}_{\mathrm{DM}}$ calimiano de $1,56 \mathrm{Ga}$. Os valores de $\varepsilon_{\mathrm{Nd}}(\mathrm{t})$ são fracamente negativos, entre $-5,9$ e $-2,95$, e indicam pouca contribuição juvenil e certa residência crustal bem marcada.

O segundo grupo está representado pelas rochas do embasamento (Figura 13), cujos protólitos diferenciaram do manto entre 2,1 e $2,39 \mathrm{Ga}$. Os valores positivos de $\varepsilon_{\mathrm{Nd}}(\mathrm{t})$ entre -0,81 e 2,99 indicam contribuições de propriedades juvenis, salvo uma amostra de biotita-gnaisse granítico que apresenta valor fracamente negativo (PAPE-125; -0,74). Ressalta-se que a amostra de augen-gnaisse (diferenciada na Figura 13 na cor vermelha), um tectonito-S (amostra PAPE-17), localiza-se no contato ocidental entre o TIc e a Faixa de Ouricuri-Bodocó. Esse contato é marcado pela ZC Trempe. Sendo assim, essa porção do embasamento foi fortemente envolvida na tectônica brasiliana.

Adicionalmente, a amostra representativa do Complexo Migmatítico (amostra PAPE-64) apresenta evolução de
$\mathrm{Nd}$ distinta das demais (destacado em verde no gráfico da Figura 13). Essa amostra apresenta valor bem menos negativo de $\varepsilon_{\mathrm{Nd}}(0)$, ca. -9 , e fracionamento adicional entre $\mathrm{Sm}$ e $\mathrm{Nd}$, sendo utilizado para o cálculo de $\mathrm{T}_{\mathrm{DM}}$ modelo de evolução de isótopos de Nd em duplo estágio (DePaolo et al., 1991).

Como pode ser visto na Tabela 5 e na Figura 13, os dados obtidos de $\mathrm{T}_{\mathrm{DM}}$ são majoritariamente do Paleoproterozoico. Cabe registrar que, até o momento, não foram encontrados dados do Arqueano no TIc, diferença significativa em relação aos inliers abordados anteriormente, e que deve ser anotada.

\section{Determinações U-Pb}

Inicialmente, foram coletadas cinco amostras em unidades distintas do TIc, observando a natureza litológica (como mostrado na Figura 11). Os dados analíticos U-Pb em zircão estão situados no Documento Suplementar - Tabela 3.

\section{Rochas do embasamento}

Foram amostradas as rochas do chamado embasamento, os ortognaisses e gnaisses migmatíticos em várias localidades geograficamente distintas e representativas do embasamento (leste, centro-oeste, norte e sul), discriminados a seguir.

A amostra PAPE-20 (Figura 12B), coletada pouco a sudoeste de Parnamirim (coordenadas 9106828 - 433270), compreende gnaisses bandados (parcialmente cisalhados) do Complexo Parnamirim, que abrange para e ortognaisses claros e bandados (orto e paragnaisses cisalhados). O augen-gnaisse (Figura 12A) do chamado "fragmento de Icaiçara" (PAPE-205) está situado na porção centro-ocidental do TIc, a oeste da Vila de Quixaba (coordenadas 911901 - 403946). Nesses mesmos gnaisses foi coletada a amostra PAPE-250, na porção mais ocidental do TIc (localidade Riacho do 
Tabela 5. Dados analíticos das determinações $\mathrm{Sm}-\mathrm{Nd}$ nas rochas do Terreno Icaiçara.

\begin{tabular}{|c|c|c|c|c|c|c|c|c|c|c|c|c|c|}
\hline Amostra & ocha & ocal & $\begin{array}{c}\text { Coorde- } \\
\text { nadas }\end{array}$ & $\begin{array}{c}\mathrm{Sm} \\
(\mathrm{ppm})\end{array}$ & $\begin{array}{c}\mathrm{Nd} \\
(\mathrm{ppm})\end{array}$ & $\begin{array}{c}{ }^{147} \mathrm{Sm} / \\
{ }^{144} \mathrm{Nd}\end{array}$ & $\begin{array}{l}{ }^{143} \mathrm{Nd} / \\
{ }^{144} \mathrm{Nd}\end{array}$ & (0) & $\begin{array}{c}\mathrm{F} \\
\mathrm{Sm} / \mathrm{Nd}\end{array}$ & $\begin{array}{c}T_{\mathrm{DM}} \\
(\mathrm{Ma}) \\
\end{array}$ & $\begin{array}{c}\varepsilon \\
\left(\mathrm{T}_{\mathrm{DM}}\right)\end{array}$ & $\begin{array}{c}\mathrm{T} 1 \\
(\mathrm{Ma}) \\
\end{array}$ & $\begin{array}{c}\varepsilon \\
(\mathrm{T} 1)\end{array}$ \\
\hline PF-123 & Meta & $m$ & $\begin{array}{c}418350 \\
9112872\end{array}$ & & 12 & 0,0872 & 0,511919 & -1 & $-0,56$ & $1.354,1$ & 4,89 & 600 & $-5,64$ \\
\hline APE-53 & (ngn & $\begin{array}{l}31 \mathrm{~km} \text { SE } \\
\text { Ouricuri }\end{array}$ & & 2,021 & 10,691 & 0,1143 & 0,51 & & $-0,42$ & 4 & 2,91 & 100 & 0,81 \\
\hline PE-250 & Ortoga & Riacho Mel & & 7,015 & 37,634 & 0,1127 & 0,511638 & & $-0,43$ & 0 & 3,25 & 2.100 & 2,99 \\
\hline APE-17 & & E & & 13,09 & 65 & 200 & 0,5 & & $-0,39$ & 8 & 3,31 & 600 & 11,28 \\
\hline$P_{2}$ & Orto & $\begin{array}{r}21,3 \mathrm{k} \\
\text { Ouric }\end{array}$ & & 5,899 & 29,052 & 0,1228 & 0,511744 & & $-0,38$ & $2.182,2$ & 3,14 & 2.100 & 2,36 \\
\hline APE-64* & & $\begin{array}{c}\text { Sul } \\
\text { Pitombeiras }\end{array}$ & & 2,192 & 8,387 & 580 & 0,5 & & $-0,20$ & , 0 & 2,83 & & 1,39 \\
\hline APE-65 & & $\begin{array}{r}\mathrm{Su} \\
\text { Pitomb }\end{array}$ & & 8,513 & 49,3 & 0,1043 & 0,51 & & $-0,47$ & $2.161,2$ & 3,17 & .100 & 2,45 \\
\hline 26 & Leuc & $\begin{array}{l}\text { Riacho } \\
\text { Carnaúbas }\end{array}$ & $\begin{array}{r}916 \\
42\end{array}$ & 1,159 & 6,606 & 1061 & 0,51 & & $-0,46$ & 2.19 & 3,11 & 2.100 & 2,01 \\
\hline PE-124 & se & $\begin{array}{c}\text { NW } \\
\text { Parnamirim }\end{array}$ & $\begin{array}{c}425421 \\
9109796\end{array}$ & 9,094 & 81 & 0,1260 & 0,5 & & $-0,36$ & 8 & 3,03 & 00 & 1,77 \\
\hline 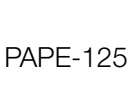 & $\begin{array}{l}\mathrm{B} \\
\mathrm{g}\end{array}$ & Pau & $\begin{array}{r}916 \\
43\end{array}$ & 3,904 & 5 & 009 & 0,5 & & $-0,49$ & 2. & 2,75 & 00 & $-0,74$ \\
\hline 政 & Granitoide & 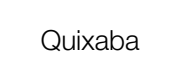 & $\begin{array}{r}41 \\
911\end{array}$ & 93 & 2 & 229 & 0 & & $=38$ & 8 & 2,91 & 0 & 1,02 \\
\hline$\triangle P F_{-10}$ & Gnaisse & $\begin{array}{l}\text { W } \\
\mathrm{Qu}\end{array}$ & & 5,516 & 33,168 & 0,1006 & 0,511344 & & $-0,49$ & $2.296,4$ & 2,92 & 2.100 & 0,51 \\
\hline APE-111 & Gnaisse & $\mathrm{B}$ & $\begin{array}{r}48 \\
911\end{array}$ & 20,584 & 126,472 & 0,0984 & 0,512091 & & $-0,50$ & $1.259,0$ & 5,11 & 600 & $-3,15$ \\
\hline & & Parr & & 9,733 & 70,322 & 0,0837 & 0,5 & & $-0,57$ & $.190,6$ & 3,12 & .100 & 1,81 \\
\hline 205 & Ortog & aba & $\begin{array}{r}911 \\
40\end{array}$ & 9,461 & 46,185 & 0,1239 & 0,511762 & & $-0,37$ & $2.178,0$ & 3,14 & 2.100 & 2,42 \\
\hline 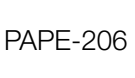 & & $a$ & & 6,958 & 50 & 0,0836 & 0,51 & & $-0,58$ & $1.254,2$ & 5,12 & 600 & $-4,32$ \\
\hline $\begin{array}{l}\text { PE- } \\
7 \mathrm{~B}\end{array}$ & & Quixaba & & 8,845 & 47,683 & 0,1122 & 0,512004 & & $-0,43$ & $1.557,6$ & 4,43 & 600 & $-5,90$ \\
\hline PAPE- & Gnaisse & 단 & $\begin{array}{c}9113554 \\
416674\end{array}$ & 21,56 & 130,837 & 0,0996 & 0,512106 & & $-0,49$ & $1.252,5$ & 5,13 & 600 & $-2,95$ \\
\hline $97-$ & & $\begin{array}{r}6 r \\
\text { Parn }\end{array}$ & $\begin{array}{c}433050 \\
9107681\end{array}$ & 3,84 & 20,69 & 0,1122 & 0,511589 & & $-0,43$ & $2.188,9$ & 3,12 & 2.100 & 2,16 \\
\hline $97-014$ & & $6 \mathrm{~km} \mathrm{~W}$ & 433050 & 3,93 & 19,63 & 0,1211 & 0,511611 & $-20,03$ & $-0,38$ & $2.365,9$ & 2,79 & 2.100 & 0,23 \\
\hline
\end{tabular}

*cálculo por duplo estágio.

Mel, BR-232; coordenadas 9120994 - 400885), que compreende ortognaisses protomiloníticos afetados por empurrão da ZC Trempe.

Rochas da Fazenda Pitombeira, na porção centro-norte do TIc, próximos das ocorrências "ofiolíticas" (coordenadas 9132530 - 425976), são compostas de migmatitos finamente bandados. A amostra PAPE-64 foi coletada no paleossoma anfibolítico a biotita de um migmatito estromatítico de grande expressão em área.

Amostra de ortognaisses leucograníticos (PAPE-303) interceptando rochas metassedimentares foi coletada em grande corte ferroviário - Ferrovia Transnordestina - a sul da Vila de Quixaba, Pernambuco, praticamente no centro geográfico do TIc (coordenadas 9113860 - 413759).

Os resultados obtidos nas rochas do embasamento (Figuras 14A a 14E) são relativamente concordantes, indicando idades do Riaciano Superior entre 2108 e $2193 \mathrm{Ma}$ (Figura 14). As amostras apresentam perda contínua de $\mathrm{Pb}$, e apesar dos altos erros no intercepto inferior, sugerem, em sua maioria, eventos sobrepostos do Brasiliano.

Pequena exceção é observada no diagrama da amostra PAPE-303, cujo intercepto inferior indica idade siluriana (a que 
não se pode atribuir significado geológico). Ressalta-se ainda que para a amostra PAPE-20 tanto as frações concordantes (elipses verdes) quanto a reta da discórdia apontam idades muito similares do Riaciano Superior (Figura 14A).

\section{Complexo Barro}

Com relação ao Complexo Barro, obtivemos amostras na Vila de Icaiçara (centro-sul do TIc) e a leste da Vila de Quixaba (ao sul de Icaiçara), Pernambuco. A amostra de ortognaisse (PAPE-301) foi coletada em afloramento a $1 \mathrm{~km}$ norte da Vila Icaiçara, Pernambuco (coordenadas 9105934-412722), e a amostra de paragnaisse (PAPE-207), coletada a leste da Vila de Quixaba, Pernambuco, a cerca de $5 \mathrm{~km}$ do contato com os ortognaisses paleoproterozoicos (coordenadas 9113152 - 417709).

A primeira amostra é de gnaisse granítico fino homogêneo, pouco laminado tectonicamente (PAPE-301). O diagrama U-Pb (Figura 15A) mostra idade concordante em $995 \pm 5,9 \mathrm{Ma}$, referente a um dos poucos cristais de zircão que preserva zoneamento setorial magmático (Figura 16, spot 3.1), assim como os cristais referentes aos spots 5.1 e 9.1, estes com idades discordantes. Quando as frações são analisadas em conjunto, apresentam intercepto superior toniano (ca. $982 \mathrm{Ma}$ ) e intercepto inferior que sugere evento Neoproterozoico. A análise das imagens de catodoluminescência sugere que os cristais de zircão mais jovens, com idades discordantes, apresentam texturas similares a zircões hidrotermais.

A amostra PAPE-207 (Figuras 15B e 15C) representa um paragnaisse rico em biotita, bandado, cortado por filões ígneos. Apesar dos poucos pontos analisados para uma rocha paraderivada, em histograma de probabilidade relativa, a amostra apresentou proveniência unimodal toniana entre 893 e 1023 Ma dos zircões detríticos amostrados, e contribuição principal de fontes com idades em torno de $950 \mathrm{Ma}$ (Figura 15C). A idade máxima de sedimentação considerada para o Complexo Barro foi obtida em cristal de zircão com ca. 893 Ma.

\section{DISCUSSÃO}

Os dados obtidos na análise litológica e estrutural no embasamento dos três terrenos se mostraram assemelhados e coerentes, no tocante às litologias presentes e nos dados geocronológicos preliminares auferidos. Há predomínio de ortognaisses e supracrustais variadas (com intensos processos de migmatização em todos eles). O TIc, como será discutido, apresenta peculiaridades não registradas nos demais terrenos.

Os dados isotópicos obtidos pela sistemática $\mathrm{Sm}-\mathrm{Nd}$ nos três terrenos são comparáveis, com valores de $\mathrm{T}_{\mathrm{DM}}$ do Paleoproterozoico ao Arqueano (entre 2,0 e 2,7 Ga) - exceção às rochas de idades e/ou retrabalhadas no Brasiliano que apresentaram $\mathrm{T}_{\mathrm{DM}}$ no Ectasiano (TAç) e Orosiriano (TSJC). As idades modelo $\mathrm{T}_{\mathrm{DM}}$ obtidas nas rochas metassedimentares do "Complexo Barro" (TIc), entre o Ectasiano e o Calimiano, por representarem composições isotópicas médias de uma dada área, podem corresponder, de um modo geral, à idade "média' da área-fonte. Vale salientar que no TIc nenhuma indicação de contribuição arqueana foi registrada, ou seja, houve ausência de formação de crosta nesse período, o que distingue (em parte) esse terreno dos demais até o momento. Característica marcante desses terrenos são os valores fracamente negativos a positivos de $\varepsilon_{\mathrm{Nd}}(t)$, o que sugere que essas rochas apresentam contribuições do manto superior com pouca ou nenhuma contribuição crustal.

As rochas dos terrenos analisados mostraram idades $\mathrm{U}-\mathrm{Pb}$ em zircão similares, com valores entre ca. 2050 e $2200 \mathrm{Ma}$,

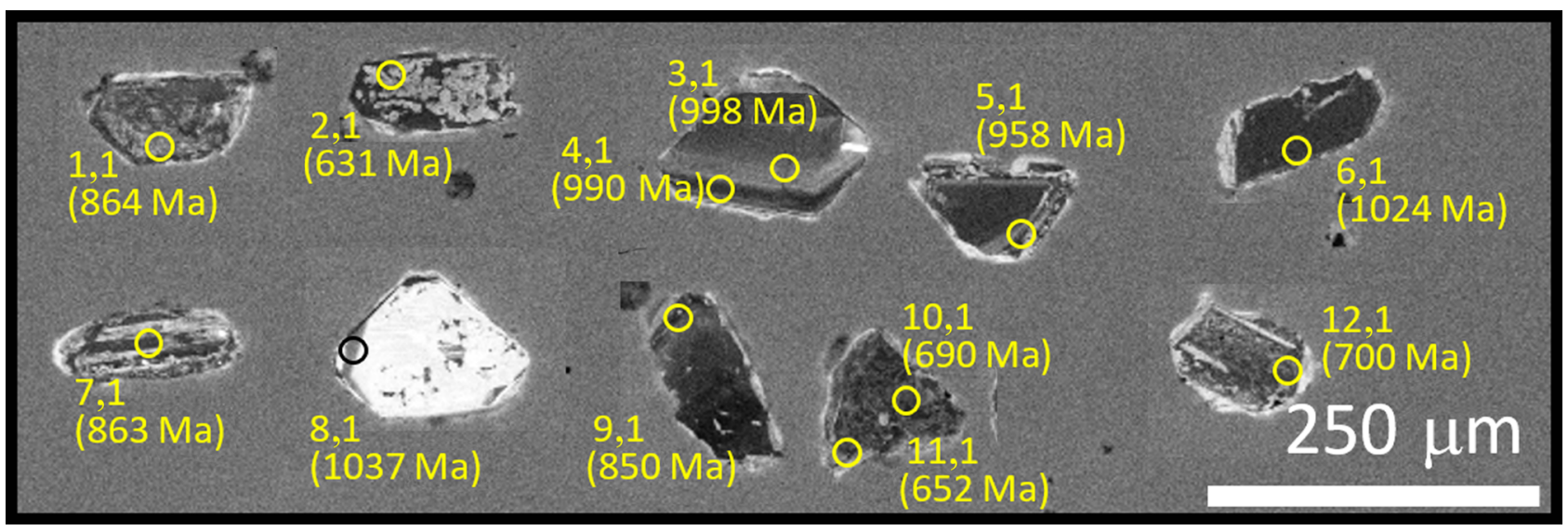

Figura 16. Imagens de catodoluminescência em cristais de zircão da amostra PAPE-301. Spots e respectivas idades ${ }^{206} \mathrm{~Pb} /{ }^{238} \mathrm{U}$ estão assinalados. 
absolutamente encaixados dentro do sistema Riaciano do Paleoproterozoico. Merece destaque uma amostra dos migmatitos do TSJC (SJCa-5a) com duas idades bem marcadas no Diagrama Concórdia: uma do Riaciano (ca. $2200 \mathrm{Ma}$ ) e outra do Sideriano Superior (ca. $2320 \mathrm{Ma}$ ), esta referente a núcleos herdados de zircão. Assim, interpreta-se que essa rocha de idade riaciana, apesar da contribuição mantélica observada pelo valor fracamente positivo de $\varepsilon_{\mathrm{Nd}}(t)$, foi originada por algum retrabalhamento de crosta sideriana.

Distintamente das demais unidades, as rochas do "Complexo Barro" se cristalizaram no Toniano Inferior. As análises U-Pb em zircões detríticos das rochas paraderivadas desse complexo indicam idade máxima de sedimentação em ca. $890 \mathrm{Ma}$, sendo a fonte principal (praticamente unimodal) desses sedimentos igualmente toniana - face ao conhecimento geológico regional. Assim, esses dados possivelmente podem ser associados a processos do Ciclo Cariris Velhos, mas não necessariamente. As características estruturais de aloctonia (napismo) sobre o TIc estão bem marcadas no campo. A definição do ciclo de evolução Neoproterozoico demanda trabalhos adicionais. Resultados geocronológicos semelhantes têm sido encontrados nos metassedimentos da Faixa Parnamirim-Verdejante (no Supergrupo Salgueiro), a leste do TIc (mas são dados ainda inéditos).

Esses três terrenos, frações poligonais irregulares do embasamento da Zona Transversal, delimitados por ZCs do Brasiliano, preenchem todas as características de terrenos tectonoestratigráficos dispersos (dispersed terranes, consoante Howell (1995), entre outros clássicos do tema).

O resumo das características dos terrenos tectonoestratigráficos gnáissico-migmatíticos da parte ocidental da Zona Transversal da Província Borborema aqui abordados, e o confronto comparativo deles, podem ser vistos em Brito Neves (2019).

\section{CONCLUSÕES}

AZona Transversal, subdomínio central da Província Borborema - delimitada por dois lineamentos E-W de magnitude transcontinental (Patos-Garoua, a norte, e Pernambuco-Adamawa, a sul) - , apresenta um clássico e variado mosaico estrutural de faixas móveis (com supracrustais neoproterozoicas) alternando com exposições de altos do embasamento paleoproterozoico. A composição, a estrutura e a alocação desses altos do embasamento - basement inliers e/ou terrenos tectonoestratigráficos - apresentam semelhanças que nos permitem admitir que são partes dispersas de um contexto mais amplo do embasamento (principalmente do Riaciano) dessas faixas móveis. Isso se complementa quando também são verificados os contextos geocronológico e geotectônico.

Do ponto de vista composicional, predominam orto e paragnaisses, com supracrustais vulcanossedimentares, em segundo plano, geralmente da fácies anfibolitos. Essas rochas do embasamento regional são, em geral, de idades do Riaciano, com alguns protólitos arqueanos muito localizados (dados U-Pb). Além dessas características semelhantes de composição e idade, os três terrenos estudados, na parte centro-ocidental da Zona Transversal (estados da Paraíba e de Pernambuco), já foram confrontados em quadro-síntese precedente (Brito Neves, 2019).

Do ponto de vista estrutural, apresentam características de domínios poligonais irregulares, fomentadas pela trama excepcional de ZCs, consorciadas com os lineamentos Patos (a norte) e Pernambuco (a sul) e suas respectivas feather faults. Essa trama de cisalhamento consorciado - discutida em vários trabalhos já publicados - é a responsável pela exaltação e pela exposição desses basement inliers, consoante vetores verticais da transpressão. Eles se comportam como mega-boudins dispersos e soerguidos pela trama cisalhante, como "altos". Porém, podemos afirmar com alguma segurança que não foram elevações precursoras da paleogeografia regional.

Os dados geocronológicos desses inliers apontam, na sua maioria, idades dentro do contexto do período Riaciano, do Paleoproterozoico, consoante os dados U-Pb em zircão, muito assemelhados. Muito localmente, de forma restrita há indicação da possibilidade de tratos (reliquiares) de rochas do arqueano (caso do TSJC).

As características litológicas, isotópicas e geocronológicas similares desses terrenos aqui apresentadas permitem considerá-los como tendo participado de uma entidade única no pré-Mesoproterozoico, que posteriormente foi segmentada e dispersa em razão da atuação das ZCs. Com relação à geotectônica, esses mega-boudins dispersos e soerguidos pela trama cisalhante, consoante todas as características anteriormente discutidas, encaixam-se na definição de terrenos tectonoestratigráficos (e.g., consoante o clássico trabalho de Howell, 1995).

\section{AGRADECIMENTOS}

Toda a pesquisa conduzida neste trabalho, viagens de campo e custos laboratoriais foram patrocinados pela Fundação de Amparo à Pesquisa do Estado de São Paulo (FAPESP), sob a égide do Processo/concessão 2013/09484-0. O Conselho Nacional de Desenvolvimento Científico e Tecnológico (CNPq) foi responsável pela Bolsa de Pesquisador 1-A do autor sênior, que muito contribuiu para que a pesquisa fosse desenvolvida. Colegas do Instituto de Geociências da Universidade de São Paulo (IGc/USP) e do Serviço Geológico do Brasil (CPRM) foram especialmente gentis, com o fornecimento de dados inéditos e por produtivas discussões, sempre que instados. A todos, nossos agradecimentos sinceros. 


\section{REFERÊNCIAS}

Archanjo, C. J., Silva, E. R., Caby, R. (1999). Magnetic fabric and pluton emplacement in a trasnpressive shear zone system: The Itaporanga prorphyritic granite pluton (northeast Brazil). Tectonophysics, 312(2-4), 331-345. https://doi. org/10.1016/s0040-1951(99)00176-6

Beurlen, H., Silva Filho, A. F., Guimarães, I. P., Brito, S. B. (1992). Proterozoic C-type eclogites hosting unusual Ti-Fe-Cr-Cu mineralization in Northeastern Brazil. Precambrian Research, 58(1-4), 195-214. https://doi. org/10.1016/0301-9268(92)90119-9

Bittar, S. M. B. (1998). Faixa Piancó-Alto Brígida: Terrenos Tectono-estratigráficos com regimes metamórficos e deformacionais contrastantes. Tese (Doutorado). São Paulo: Instituto de Geociências - USP. https://doi. org/10.11606/T.44.1999.tde-18112015-101917

Brito Neves, B. B. (2019). Terrenos Tectonoestratigráficos e/ou "Maciços". Evolução do conceito e aplicação na Zona Transversal da Província Borborema. Terrae Didática, 15, e019020. https://doi.org/10.20396/td.v15i0.8655818

Brito Neves, B. B., Campos Neto, M. C. (2016). A Faixa de Dobramentos do Rio Salgado- noroeste da Zona TransversalProvíncia Borborema (PB-CE). Geologia USP. Série Cientifica, 16(3), 3-17. https://doi.org/10.11606/issn.23169095.v16i3p3-17

Brito Neves, B. B., Campos Neto, M. C., Van Schmus, W. R., Santos, E. J. (2001). O Sistema Pajeú-Paraíba e o Maciço São Jose de Campestre no leste da Borborema. Revista Brasileira de Geociências, 31(2), 173-184. https:// doi.org/10.25249/0375-7536.2001312173184

Brito Neves, B. B., Passarelli, C. R., Basei, M. A. S., Santos, E. J. (2003). Idades U-Pb em Zircão de Alguns Granitos Clássicos da Província Borborema. Geologia USP. Série Cientifica, 3, 25-38. https://doi.org/10.5327/ S1519-874X2003000100003

Brito Neves, B. B., Santos, E. J., Fuck, R. A., Santos, L. M. (2016). A preserved early Ediacaran magmatic arc at the northernmost portion of the Transversal Zone, central subprovince of the Borborema Province, Northeastern South America. Brazilian Journal of Geology, 46(4), 491-508. https://doi.org/10.1590/2317-4889201620160004

Brito Neves, B. B., Van Schmus, W. R., Campos Neto, M. C. (2018). Sistema de Dobramentos Piancó-Alto Brígida (PE-PB-CE), Regionalização geotectônica e geocronologia.
Geologia USP. Série Cientifica, 18(4), 149-171. https://doi. org/10.11606/issn.2316-9095.v18-142182

Centro de Tecnologia e Geociências - Universidade Federal de Pernambuco / Departamento Nacional da Produção Mineral (CTG-UFPE/DNPM) (1983). Projeto Extremo Oeste de Pernambuco, Escala 1/100.000. Relatório de conclusão do curso de Geologia. Universidade Federal de Pernambuco.

Cruz, R. F., Marinho, M. S., Oliveira, R. G. (2012). Carta Geológica Folha SC. 24-V-B-II Parnamirim. Brasil: Serviço Geológico do Brasil.

DePaolo, D. J. (1988). Neodymium Isotope Geochemistry: An Introduction. Heildeberg: Spring Verlag, 187 p. https:// doi.org/10.1007/978-3-642-48916-7

DePaolo, D. J., Linn, A.M., Schubert, G. (1991). The continental age distribution: methods of determining mantle separation ages from $\mathrm{Sm}-\mathrm{Nd}$ isotopic data and application to the southwestern United States. Journal of Geophysical Research, 96(B2), 2071-2088. https://doi.org/10.1029/90JB02219

Gibbons, W. (1994). Suspect Terranes. In: P. L. Hancock (Ed.), Continental Deformation (p. 305-319). Oxford, Nova York, Seoul, Tóquio: Pergamon Press.

Gomes, H. A. (2000). Carta Geológica da Folha SB-24-Z. Serra Talhada SB-24-Z-C. Escala 1/250.000. Recife/Brasília: Serviço Geológico do Brasil (CPRM).

Gomes, H. A. (2001). Mapa Geológico do Estado de Pernambuco, escala 1/500.000. Brasília/Recife: Serviço Geológico do Brasil (CPRM)/Secretaria de Desenvolvimento, Turismo e Esportes do Governo de Pernambuco.

Guimarães, I. P., Van Schmus, W. R., Brito Neves, B. B., Bittar, S. M., Silva Filho, A. F., Armstrong, R. (2012). U Pb zircon ages of orthogneisses and supracrustal rocks of the Cariris Velhos belt: onset of Neoproterozoic rifting in the Borborema Province, NE Brazil. Precambrian Research, 192195, 52-77. https://doi.org/10.1016/j.precamres.2011.10.008

Howell, D. G. (1995). Principles of Terrane Analysis: New Applications for the Global Tectonics. 2. ed. Londres: Chapman \& Hall, 235 p.

Kozuch, M. (2003). Isotopic and Trace elements Geochemistry of Early Neoproterozoic Gneissic and Metavolcanic Rocks in the CaririsVelhosOrogen of the Borborema Province, Brazil, and their bearing on Tectonic Setting. Tese (PhD). Lawrence: Department of Geology, Faculty of the Graduate School, University of Kansas, 199 p. 
Lages, G. A., Dantas, E. L. (2016). Floresta and Bodocó Mafic-Ultramafic Complexes, western Borborema Province, Brazil: Geochemical and isotope constraints for evolution of a Neoproterozoic arc environment and retro-eclogite hsoted Ti-mineralization. Precambrian Research, 280, 95-119. https://doi.org/10.1016/j.precamres.2016.04.017

Mariano, G. (1989). Magma mixing of a potassic calcalkaline pluton: the Itaporanga batholith, State of Paraiba, Northeast Brazil. Thesis (PhD). Athens: Department of Geology, University of Georgia, $180 \mathrm{p}$.

Medeiros, V. C. (2004). Evolução geodinâmica e condicionamento estrutural dos terrenos Piancó-Alto Brigida e Alto Pajeú, Domínio da Zona Transversal, NE do Brasil. Tese (Doutorado). Natal: Centro de Ciências Exatas e da Terra - UFRN, 185 p. Disponível em: <http://rigeo.cprm. gov.br/jspui/handle/doc/105>. Acesso em: 28 jul. 2020.

Santos, E. J. (1996). Ensaio Preliminar sobre Terrenos e tectônica acrescionária na Província Borborema. $X X X I X$ Congresso Brasileiro de Geologia, 47-50. Salvador: SBG. Disponível em: $<$ http://www.sbgeo.org.br/home/pages/44>. Acesso em: 28 jul. 2020.
Santos, E. J., Ferreira, C. A., Silva Junior, J. M. P. (2002). Mapa Geológico do Estado da Paraíba, escala 1/500.000. Recife / João Pessoa: CPRM - Serviço Geológico do Brasil/ Secretaria Extraordinária de Recursos Minerais da Paraíba.

Santos, E. J., Oliveira, R. G., Paiva, I. P. (1997). Terrenos no domínio transversal da Província Borborema: controles sobre acresção e retrabalhamento crustais ao sul do Lineamento Patos. XVII Simpósio de Geologia do Nordeste, 141-144. Fortaleza: SBG/Núcleo Nordeste.

Santos, E. J., Souza Neto, J. A., Silva, M. R. R., Beurlen, H., Cavalcanti, J. A. D., Dias, V., M., Costa, A. F., Santos, L. C. M. L., Santos, R. B. (2014). Metalogênese das porções norte e central da Província Borborema. In: M. G. Silva, M. B. Rocha Neto, H. Jost, R. Kuyumijian (Eds.), Metalogênese das Províncias Tectônicas Brasileiras, 343-388. Belo Horizonte: CPRM - Serviço Geológico do Brasil.

Van Schmus, W. R., Kozuch, M., Brito Neves, B. B. (2011). Precambrian history of the Zona Transversal of the Borborema Province, NE Brazil. Journal of South American Earth Sciences, 31(2-3), 227-252. https://doi.org/10.1016/j. jsames.2011.02.010 